\title{
TNF- $\alpha$ is critical for antitumor but not antiviral T cell immunity in mice
}

\author{
Thomas Calzascia, Marc Pellegrini, Håkan Hall, Laurent Sabbagh, Nobuyuki Ono,
} Alisha R. Elford, Tak W. Mak, and Pamela S. Ohashi

The Campbell Family Institute for Breast Cancer Research, Ontario Cancer Institute, Toronto, Ontario, Canada.

\begin{abstract}
TNF- $\alpha$ antagonists are widely used in the treatment of inflammatory and autoimmune diseases, but their use is associated with reactivation of latent infections. This highlights the importance of TNF- $\alpha$ in immunity to certain pathogens and raises concerns that critical aspects of immune function are impaired in its absence. Unfortunately, the role of TNF- $\alpha$ in the regulation of T cell responses is clouded by a myriad of contradictory reports. Here, we show a role for TNF- $\alpha$ and its receptors, TNFR1 and TNFR2, specifically in antitumor immunity. TNF- $\alpha-$ deficient mice exhibited normal antiviral responses associated with strong inflammation. However, TNF- $\alpha$ / TNFR1-mediated signals on APCs and TNF- $\alpha$ /TNFR2 signals on T cells were critically required for effective priming, proliferation, and recruitment of tumor-specific T cells. Furthermore, in the absence of TNF- $\alpha$ signaling, tumor immune surveillance was severely abrogated. Finally, treatment with a CD40 agonist alone or in combination with TLR2 stimuli was able to rescue proliferation of TNF- $\alpha$-deficient $T$ cells. Therefore, TNF- $\alpha$ signaling may be required only for immune responses in conditions of limited immunostimulatory capacity, such as tumor surveillance. Importantly, these results suggest that prolonged continuous TNF- $\alpha$ blockade in patients may have long-term complications, including potential tumor development or progression.
\end{abstract}

\section{Introduction}

TNF- $\alpha$ was originally identified for its capacity to induce hemorrhagic necrosis of solid tumors (1). It is now recognized as a pleiotropic cytokine that is critically required in multiple biological processes. While TNF- $\alpha$ production is restricted to a relatively small subset of cells, its 2 receptors, TNF receptor 1 (TNFR1; p55) and TNFR2 (p75), are almost ubiquitously expressed. These receptors transduce TNF- $\alpha$ signals and are responsible for a broad range of downstream effects, including apoptosis, cell activation, survival, and proliferation $(2,3)$.

Deregulated or excessive production of TNF- $\alpha$ has been implicated in the pathogenesis of several debilitating inflammatory conditions such as RA, psoriatic arthritis, and Crohn disease (4, $5)$. Given the potential pathological role of TNF- $\alpha$, several therapeutic agents that target and block its activity have been developed and are in clinical use $(4,6,7)$. Despite the successful use of TNF- $\alpha$ inhibitors in the treatment of inflammatory conditions, the exact role of TNF- $\alpha$ in the etiology and pathogenesis of these diseases is still poorly understood $(4,8)$. Furthermore, the mechanistic role of TNF- $\alpha$ in immune activation at the level of cellular interactions has yet to be clearly defined.

There are numerous inconsistencies and contradictions between in vitro experiments that propose potential functions of this cytokine and in vivo studies, using TNF- $\alpha$ overexpression, TNF- $\alpha$ blockade, or gene targeting in animals, which fail to confirm the results. In various models, TNF- $\alpha$ or its receptors were reported to affect certain phases of the immune process, including innate immune activation or DC maturation/recruitment (9-11), T cell priming (4, 12-16), T cell proliferation (17), T cell recruitment

Nonstandard abbreviations used: GP, glycoprotein; LCMV, lymphocytic choriomeningitis virus; Pam3, Pam3Cys-SKKKK; PDLN, pancreatic draining LN; RIP, rat insulin promoter; Tag, SV40 large T antigen; TNFR, TNF receptor.

Conflict of interest: The authors have declared that no conflict of interest exists. Citation for this article: J. Clin. Invest. 117:3833-3845 (2007). doi:10.1172/JCI32567.
(18-20), T cell function (21-24), or pathogen clearance $(25,26)$. In some studies the exact mechanism is not thoroughly defined, but TNF- $\alpha$ is shown to be critically required for efficient $T$ cell immune responses (27-33). In contrast, in other experimental systems, either no requirement of TNF receptors was reported for the efficient in vivo activation and primary expansion of T cells (25, $31,34)$ or suppression of $\mathrm{T}$ cell immunity was observed, an effect related to the timing of TNF- $\alpha$ administration during the immune process $(4,7,13,35,36)$. The discrepancies and confusion are best exemplified by the multiple in vitro studies providing evidence that TNF- $\alpha$ and TNFR 2 can induce and costimulate T cell activation and proliferation (37-44), but only one in vivo study supports the physiological relevance of these in vitro observations (45).

In view of the different mouse strains, antigenic triggers, target tissues, inflammatory conditions, and subsets of immune effectors inherent in all the different experimental models, it is difficult to reconcile the contradicting results and have a clear picture of TNF- $\alpha$ 's role in T cell immunity. To explain these inconsistencies, we hypothesized that the nature of the antigen that initiates the immune response, and the context in which it is presented, will have a direct role in creating a proinflammatory milieu and this will be a critical factor that determines the relevance of TNF- $\alpha$ and its receptors in the immune process. Indeed, strong inflammatory responses are likely to be associated with the production of other factors that may overcome the need for TNF- $\alpha$. In contrast, in situations where immunostimulatory conditions are limiting, such as during the development of spontaneous tumors, TNF- $\alpha$ 's activity would become more prominent and perhaps an essential requirement at multiple stages of the immune process.

With the advent of TNF- $\alpha$ antagonist therapy in autoimmune diseases, it has become imperative to understand the consequences of TNF- $\alpha$ blockade, both immediate and late, particularly for potential disease complications that have a long latency and may not become apparent for many years. For this reason, and given the widespread use of these biological agents, it is vital to explore the 

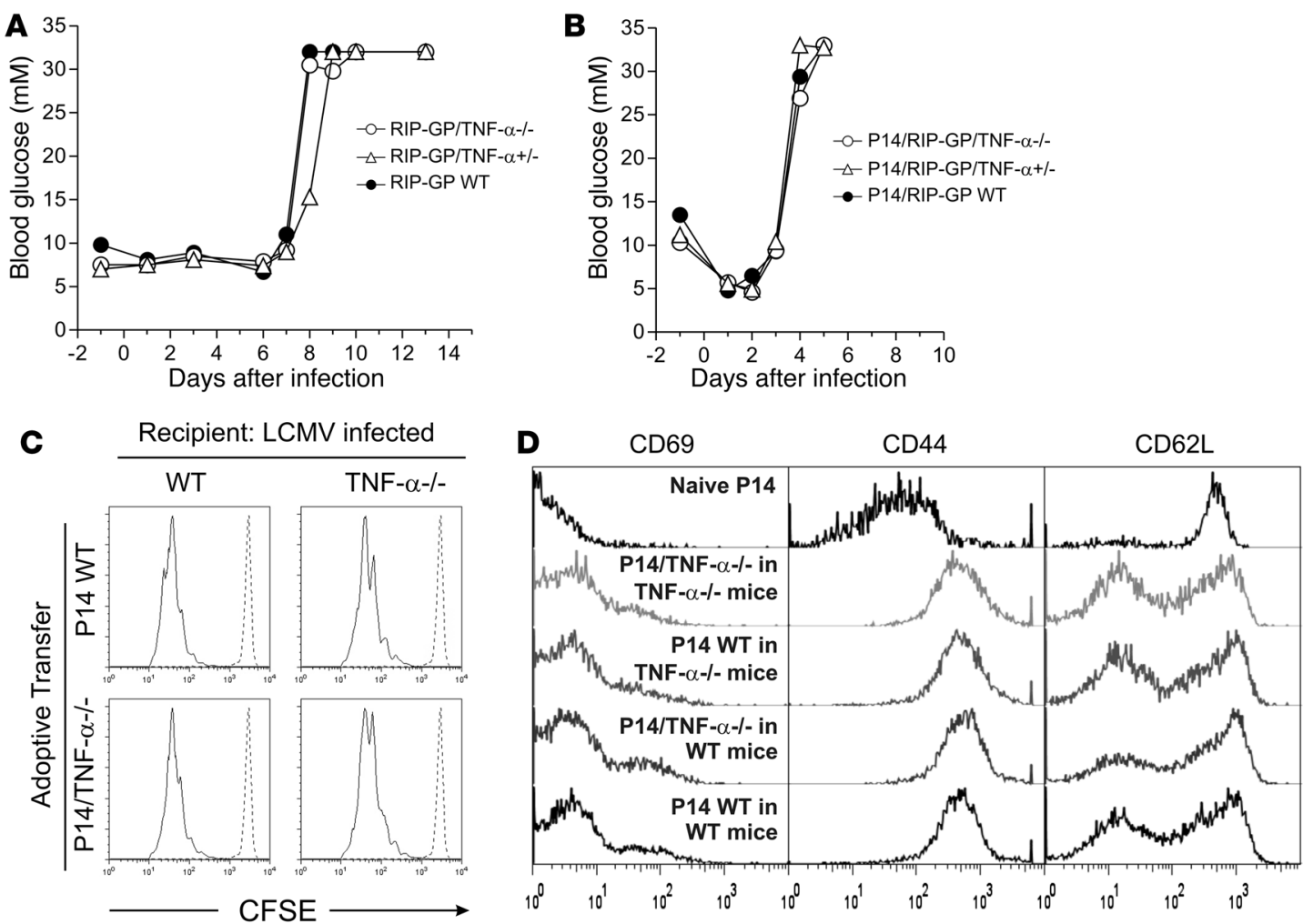

\section{Figure 1}

The absence of TNF- $\alpha$ does not alter the kinetics or magnitude of LCMV-induced autoimmune diabetes in RIP-GP or P14/RIP-GP animals. (A) RIP-GP mice were infected with LCMV Arm. Blood glucose levels were measured at multiple time points and used as an indication of islet $\beta$ cell autoimmune destruction. Blood glucose levels of 1 mouse representative of at least 6 mice are shown for each genotype. (B) P14/RIP-GP animals were infected with LCMV Arm, and blood glucose was monitored as in A. Blood glucose levels of 1 mouse representative of at least 5 mice are shown for each genotype. (C) CFSE-labeled P14 WT or TNF- $\alpha^{-/-}$CD8 ${ }^{+}$T cells were adoptively transferred into WT or TNF- $\alpha^{-/-}$mice infected 3 days previously with LCMV Arm. The extent of T cell proliferation was assessed by CFSE dilution in spleens 3 days later (solid lines). Histograms are gated on $\mathrm{CFSE}+\mathrm{CD} 8^{+} \mathrm{V} \alpha 2^{+}$cells and are representative of 3 independent animals per condition. Dashed lines indicate the $\mathrm{CFSE}$ profile of undivided cells. (D) Expression of CD69, CD44, and CD62L on CFSE ${ }^{+} \mathrm{CD}^{+}{ }^{+} \mathrm{V} \alpha 2^{+}$cells from C.

role of TNF- $\alpha$ in the development, progression, and immune surveillance of tumors. The relevance of these issues is also highlighted by a recent meta-analysis that suggests a possible link between anti-TNF- $\alpha$ therapy and an increased incidence of malignancies in RA patients (46).

In order to address these issues, we compared the in vivo consequences of TNF- $\alpha$ deficiency on the multiple phases (priming, $\mathrm{T}$ cell expansion, recruitment, and effector function) of a $\mathrm{T}$ cell immune response directed against the same antigen in 2 contexts: (a) as a viral protein coupled with strong inflammation that results in pathological autoimmunity; or (b) as a tumor-associated antigen. The lymphocytic choriomeningitis virus (LCMV) glycoprotein (GP) provided an ideal model for this purpose. LCMV infection has been extensively used to study immunological responses in multiple animal models. In addition, the previously described RIP-GP transgenic mice (47), in which the rat insulin promoter (RIP) drives the expression of LCMV GP in pancreatic islet $\beta$ cells, provided a tool to assess the efficiency of a virally induced immune response. Constitutive LCMV GP expression in the pancreas of RIP-GP mice is not associated with significant central or peripheral deletion of GP-reactive $\mathrm{CD}^{+} \mathrm{T}$ cells, nor does it result in spontaneous GP-specific T cell immunity (47). However, following LCMV infection, there is an expansion of GP-specific CD8 ${ }^{+} \mathrm{T}$ cells, resulting in autoimmune destruction of $\beta$ cells and the development of diabetes (47). Thus, LCMV infection can provide a strong inflammatory stimulus to initiate GP-specific $\mathrm{T}$ cell responses to a model self antigen.

In order to study whether TNF- $\alpha$ is critical for spontaneous antitumor responses, we intercrossed RIP-GP mice with RIP-Tag2 transgenic mice. In RIP-Tag2 mice, the RIP promoter regulates SV40 large $\mathrm{T}$ antigen (Tag) expression, resulting in progressive hyperproliferation and transformation of $\beta$ cells (48). We previously reported that tumor progression in $\mathrm{RIP}(\mathrm{GP} \times \mathrm{Tag} 2)$ does not result in the deletion or inactivation of GP-specific $\mathrm{CD}^{+} \mathrm{T}$ cells $(49,50)$. However, the growth of GP-expressing tumors provides sufficient antigen to promote the activation, proliferation, and recruitment of adoptively transferred naive P14 GP-specific CD8 ${ }^{+}$ $\mathrm{T}$ cells to the tumor site (50).

By crossing RIP-GP, RIP-Tag2, and P14 TCR transgenic mice on TNF- $\alpha-$, TNFR1-, and TNFR2-deficient (-/-) backgrounds, we could address the relevance of TNF- $\alpha$ and its receptors on the multiple phases of GP-specific $\mathrm{CD}^{+} \mathrm{T}$ cell responses initiated by a pathogen or tumor growth. We provide evidence that TNF- $\alpha$ and its receptors critically affect multiple events in an immune response initiated by a tumor antigen, while TNF- $\alpha$ becomes dispensable when $\mathrm{T}$ cells are activated in the context of a strong 

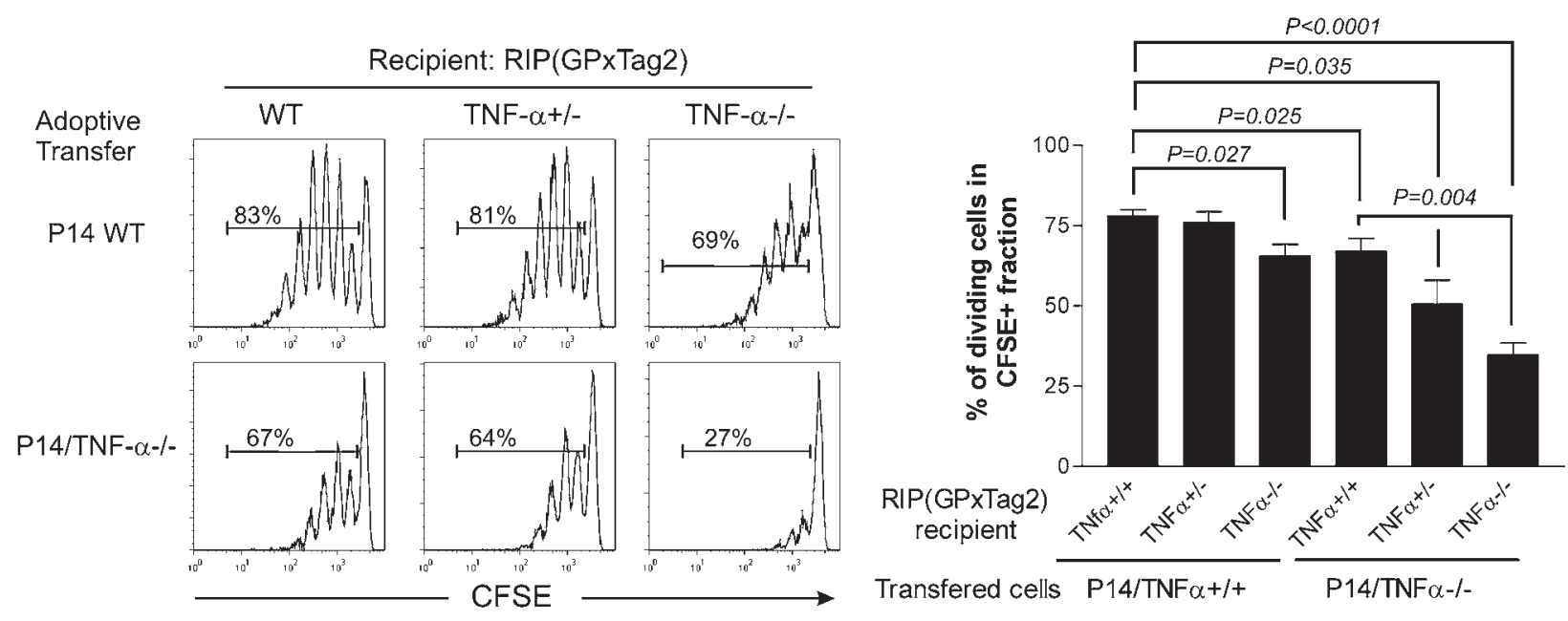

Figure 2

Intrinsic and extrinsic defects impair T cell proliferation in response to spontaneous malignancies in TNF- $\alpha^{-/-}$mice. CFSE-labeled naive P14 WT or P14/TNF- $\alpha^{-1-}$ CD8 ${ }^{+}$T cells were adoptively transferred into the indicated RIP(GP $\times$Tag2) hosts. Proliferation of CFSE-labeled cells was assessed 3 days later in PDLN. Histograms are gated on $C F S E+C D 8^{+} V_{\alpha 2}{ }^{+}$cells. The percentage in each histogram indicates the proportion of dividing cells among the CFSE-labeled population. A summary and mean of the proportion of proliferating cells observed in individual animals is presented. Error bars indicate SEM The indicated differences are statistically significant. Number of mice analyzed: WT $\rightarrow$ WT: $n=6$; WT $\rightarrow$ TNF- $\alpha^{+--}: n=3$; WT $\rightarrow$ TNF- $\alpha^{-1-}: n=6$; TNF- $\alpha^{-1-} \rightarrow$ WT: $n=4$; TNF- $\alpha^{-1-} \rightarrow$ TNF- $\alpha^{+/-}: n=3$; and TNF- $\alpha^{-1-} \rightarrow$ TNF- $\alpha^{-1-}: n=5$.

inflammatory response. Therefore, the inflammatory milieu in which an antigen is presented is a critical factor determining the relevance of TNF- $\alpha$ in the $\mathrm{T}$ cell immunity.

\section{Results}

The absence of TNF- $\alpha$ does not impair virally induced immune responses and pathology. To examine whether TNF- $\alpha$ plays an important role in virus-induced proinflammatory responses in vivo and their pathological consequences, we used the RIP-GP model. In RIP-GP and P14/RIP-GP mice, LCMV infection activates GP-specific CD8 ${ }^{+}$ $T$ cells that subsequently mediate the autoimmune destruction of GP-expressing islet $\beta$ cells, leading to the induction of hyperglycemia and diabetes (47). To evaluate the participation of endogenous TNF- $\alpha$ in postpriming events after LCMV infection, we monitored the kinetics of virally induced diabetes in these transgenic models. No major difference in the kinetics of hyperglycemia development was observed between single-transgenic RIP-GP or double-transgenic P14/RIP-GP mice on a TNF- $\alpha$ WT, heterozygous (+/-), or null $(-/-)$ background (Figure 1, A and B). This suggests that TNF- $\alpha$ 's functions are dispensable for the events leading to the $\mathrm{CD}^{+}$ $\mathrm{T}$ cell-mediated autoimmune destruction of GP-expressing islet $\beta$ cells following LCMV infection.

In order to further examine the role of TNF- $\alpha$ in T cell responses to viral infection, CSFE-labeled naive P14 WT or TNF- $\alpha^{-/-} \mathrm{CD} 8^{+} \mathrm{T}$ cells were adoptively transferred into WT or TNF- $\alpha^{-/}$LCMV-infected recipients. After 3 days TNF- $\alpha^{-/-}$and WT T cells proliferated to a similar degree (Figure 1C) and showed the same expression pattern of activation markers (Figure 1D). We then quantified the number of T cells specific for the H-2 $\mathrm{D}^{\mathrm{b}}$-restricted GP33, GP276, and NP396 LCMV epitopes in the spleen of WT and TNF- $\alpha^{-/-}$mice following LCMV infection. At day 8 there was a significant increase in NP396- but not GP33- and GP276-specific CD8 ${ }^{+} \mathrm{T}$ cells in TNF- $\alpha^{-/-}$ animals. However, at day 15 all populations were modestly but significantly higher in TNF- $\alpha^{-/-}$than in control mice (Supple- mental Figure 1; supplemental material available online with this article; doi:10.1172/JCI32567DS1). The significance of this change remains unclear. Collectively, these data indicate that TNF- $\alpha$ is not critical for the primary LCMV immune response.

$T N F-\alpha$ is critical for immune responses to tumor-associated antigens and is required on both $T$ cell and non-T cell populations. We previously reported that naive $\mathrm{P} 14 \mathrm{CD}^{+} \mathrm{T}$ cells adoptively transferred into tumor-bearing $\mathrm{RIP}(\mathrm{GP} \times \mathrm{Tag} 2)$ mice rapidly proliferate in response to cross-presented LCMV GP antigens in the pancreatic draining LN (PDLN) draining the pancreas and subsequently infiltrate the tumor (50). In order to assess whether TNF- $\alpha$ was required for the activation and proliferation of $\mathrm{P} 14 \mathrm{CD}^{+} \mathrm{T}$ cells to tumor antigens in vivo, we adoptively transferred CFSE-labeled naive P14 WT $\mathrm{CD}^{+} \mathrm{T}$ cells into WT, TNF- $\alpha^{+/-}$, or TNF- $\alpha^{-/-} \mathrm{RIP}(\mathrm{GP} \times \mathrm{Tag} 2)$ transgenic mice and analyzed the extent of $\mathrm{T}$ cell proliferation in PDLN 3 days following adoptive transfer by examining the dilution of CFSE dye. While P14 WT CD8 ${ }^{+} \mathrm{T}$ cells proliferated extensively in PDLN of WT and TNF- $\alpha^{+/-}$RIP(GP $\times$Tag2) hosts, T cell proliferation was significantly reduced in PDLN of RIP(GP $\times$ Tag2)/ TNF- $\alpha^{-/-}$mice (Figure 2 ). These data suggest that TNF- $\alpha$ production by host cells enhances the efficiency and ability of cross-presenting APCs within PDLN to stimulate GP-specific CD8 ${ }^{+} \mathrm{T}$ cells.

The major sources of TNF- $\alpha$ in vivo are APCs such as macrophages and DCs. However, T cell-derived TNF- $\alpha$ may also influence T cell proliferation in vivo (45). In order to assess the relative contribution of TNF- $\alpha$ production by $\mathrm{T}$ lymphocytes and its impact on $\mathrm{T}$ cell activation, we adoptively transferred CFSE-labeled P14/TNF- $\alpha^{-/-}$ $\mathrm{CD}^{+} \mathrm{T}$ cells into WT, TNF- $\alpha^{+/-}$, or TNF- $\alpha^{-/-}$tumor-bearing RIP(GP $\times$ Tag2) mice. After 3 days the proliferation of adoptively transferred $\mathrm{P} 14 / \mathrm{TNF}^{-} \alpha^{-/-} \mathrm{CD}^{+} \mathrm{T}$ cells was significantly reduced compared with that of P14 WT CD8 ${ }^{+}$T cells in WT and TNF- $\alpha^{+/-}$RIP(GP $x$ Tag2) hosts (Figure 2). Importantly, we observed a profound reduction in proliferation when $\mathrm{P} 14 / \mathrm{TNF}-\mathrm{\alpha}^{-/-} \mathrm{CD} 8^{+} \mathrm{T}$ cells were trans-

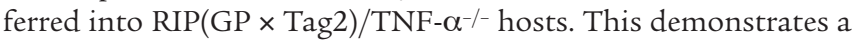


A

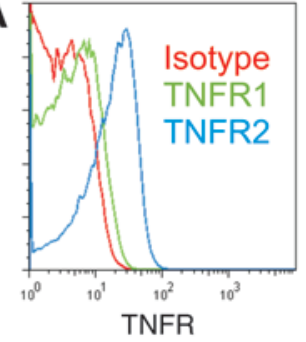

C
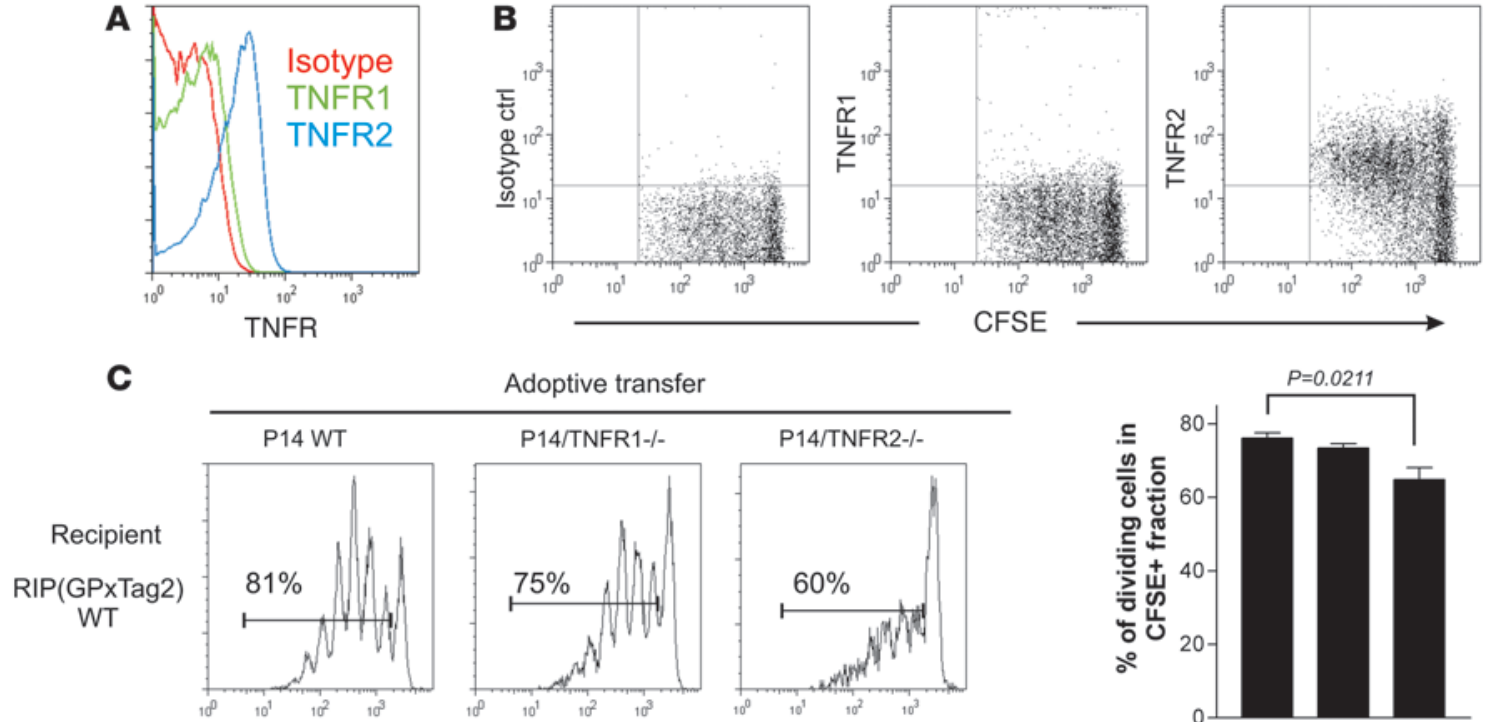

Adoptive transfer
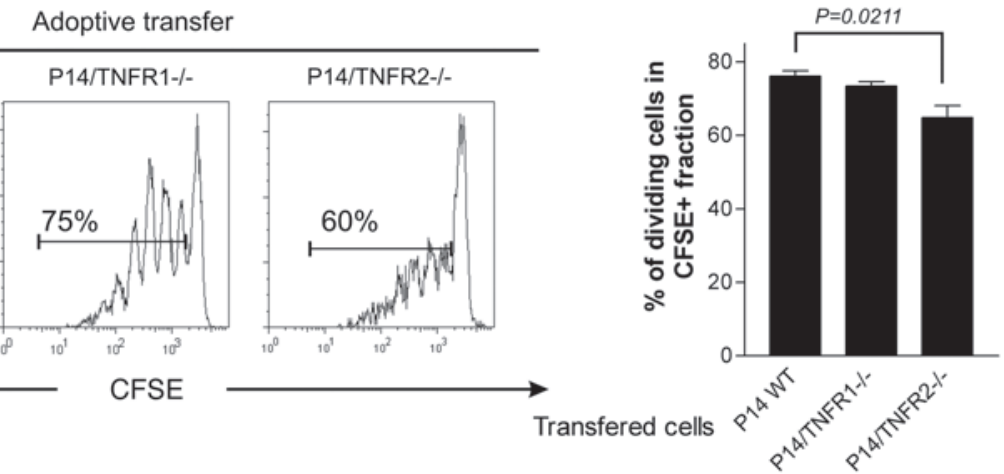

D

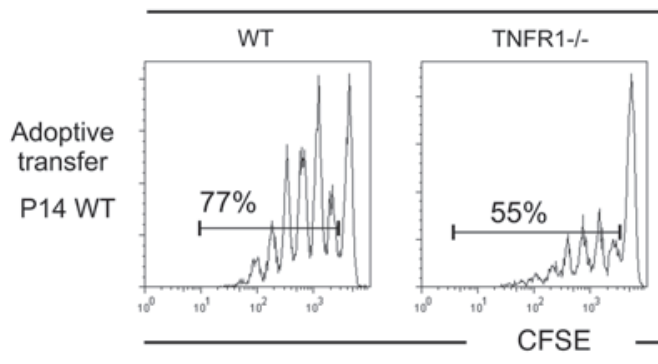

Recipient: RIP(GPxTag2)
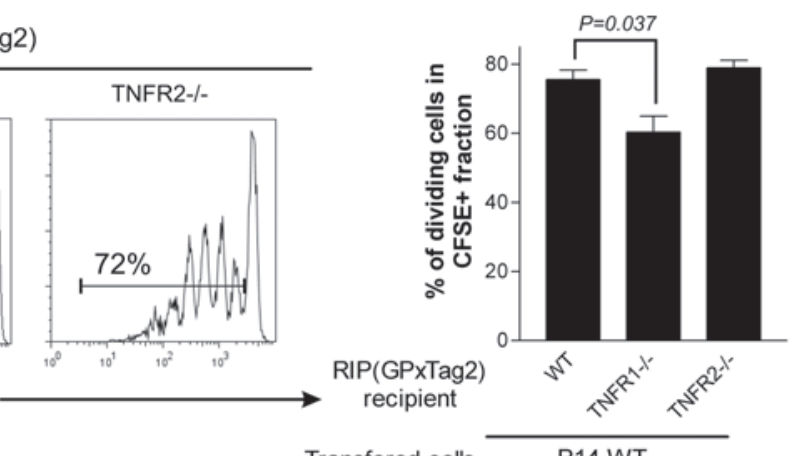

Figure 3

TNFR2 but not TNFR1 expression on T cells integrates TNF- $\alpha$-dependent costimulatory signals. (A) TNFR1 and TNFR2 expression on naive $\mathrm{P} 14 \mathrm{~T}$ cells was assessed by gating on $\mathrm{CD} 8^{+} \mathrm{V} \alpha 2^{+}$cells in inguinal LN (iLN) of P14/RIP(GP $\times$Tag2) animals. (B) Proliferating P14 cells display high levels of TNFR2 expression. CFSE-labeled naive P14 WT CD8+ T cells were adoptively transferred into WT RIP(GP $\times$ Tag2) hosts. TNFR1 and TNFR2 modulation during proliferation was assessed 3 days later in PDLN. Dot plots are gated on $\mathrm{CFSE}+\mathrm{CD} 8^{+} \mathrm{V} \alpha 2^{+}$cells. The data shown are representative of 3 independent experiments. (C) CFSE-labeled naive P14 WT, P14/TNFR1 ${ }^{-1-}$, or P14/TNFR2 $2^{-/-}$CD8 ${ }^{+}$T cells were adoptively transferred into WT RIP(GP $\times$ Tag2) hosts. Proliferation of CFSE-labeled cells was assessed 3 days later in PDLN. Histograms are gated on $\mathrm{CFSE}{ }^{+} \mathrm{CD}^{+}{ }^{+} \mathrm{V} \alpha 2^{+}$cells. The percentage in each histogram indicates the proportion of dividing cells among the CFSE-labeled population. A summary and mean of the proportion of proliferating cells observed in individual animals is presented. Error bars indicate SEM. Number of mice analyzed: P14 WT: $n=7$; P14/TNFR1-l-: $n=6$; P14/TNFR2--- $n=7$. (D) CFSE-labeled naive P14 WT CD8+ T cells were adoptively transferred into WT, TNFR1 ${ }^{-1}$, or TNFR2 ${ }^{-1-}$ RIP(GP $\times$ Tag2) recipients of the indicated genotype. Proliferation of CFSE-labeled cells was assessed 3 days later in PDLN. Histograms were gated on $\mathrm{CFSE}{ }^{+} \mathrm{CD} 8^{+} \mathrm{V} \alpha 2^{+}$cells. A summary and mean of the proportion of proliferating cells observed in individual animals is presented. Error bars indicate SEM. A significant reduction in proliferation was observed in TNFR1 $1^{-/-}$RIP(GP $\times$Tag2) mice $(P=0.037)$. Number of mice analyzed: WT RIP(GP $\times$ Tag2 $): n=5 ; \operatorname{RIP}(\mathrm{GP} \times \operatorname{Tag} 2) / \mathrm{TNFR}^{-1-}: n=8 ; \operatorname{RIP}(\mathrm{GP} \times \mathrm{Tag} 2) / \mathrm{TNFR} 2^{-/-}: n=3$.

clear synergistic effect between host and T cell-derived TNF- $\alpha$ and its impact on the respective cell populations (Figure 2). Therefore, in contrast to its limited role in in vivo proliferative responses to viral antigens, TNF- $\alpha$ is critical in promoting $\mathrm{T}$ cell proliferation to cross-presented tumor antigens.

TNFR2 but not TNFR1 on P14 T cells acts to costimulate T cells and enhance proliferation. Two distinct receptors, TNFR1 and TNFR2, mediate the multiple effects of TNF- $\alpha$ (3). We could detect expression of both receptors on naive P14 cells, but TNFR2 was expressed at higher levels than TNFR1 (Figure 3A). Importantly, TNFR2 was highly expressed on P14 cells proliferating in the PDLN of adoptively transferred RIP(GP $\times$ Tag2) hosts (Figure 3B). In contrast, no clear modulation of TNFR1 expression was detected on the same cells. To determine whether the lack of TNFR1 or TNFR2 on P14 cells affected their proliferation in vivo in response to tumor antigens, CFSE-labeled P14 WT, P14/TNFR1 $1^{-/}$, or P14/TNFR2 ${ }^{-/-} \mathrm{CD}^{+}$ $\mathrm{T}$ cells were adoptively transferred into WT RIP $(\mathrm{GP} \times \mathrm{Tag} 2)$ tumorbearing hosts, and the extent of $\mathrm{T}$ cell proliferation in PDLN was assessed 3 days later (Figure 3C). While P14/TNFR1-/- and P14 WT T cells proliferated to a similar extent, there was a significant 
A
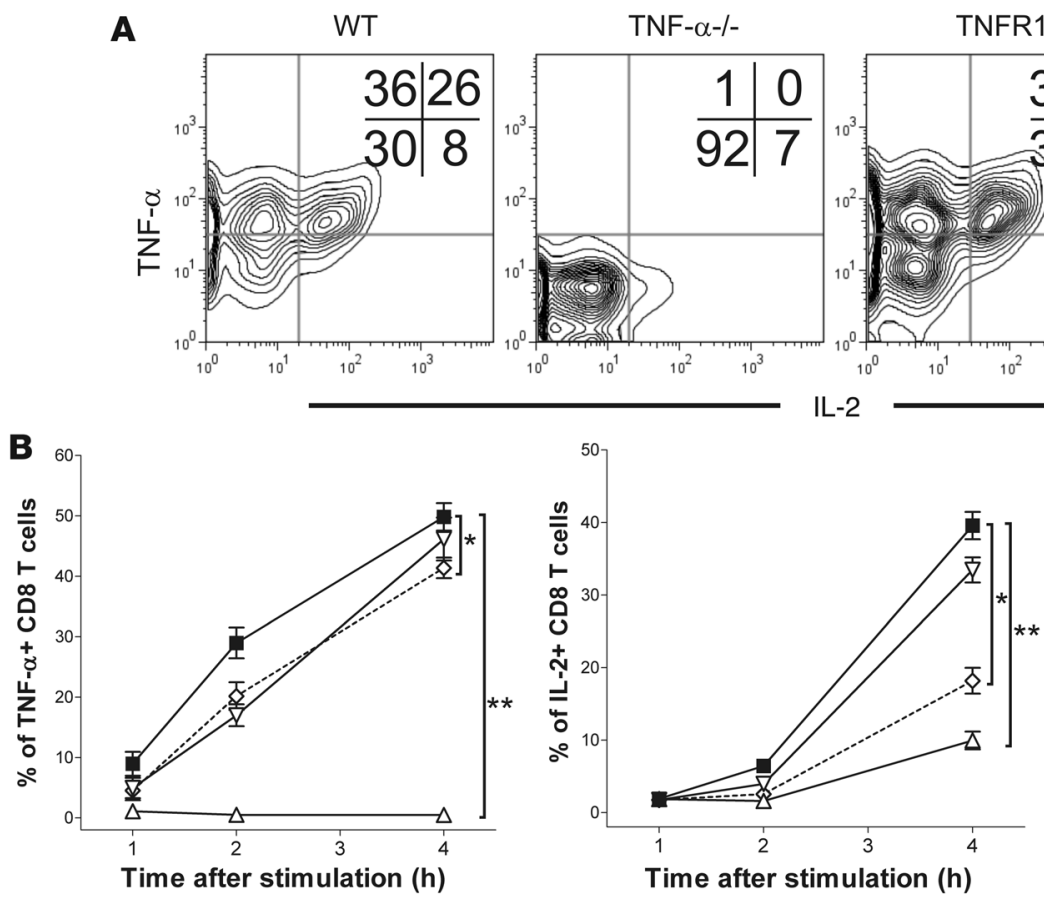

TNFR1-I-

TNFR2-I-
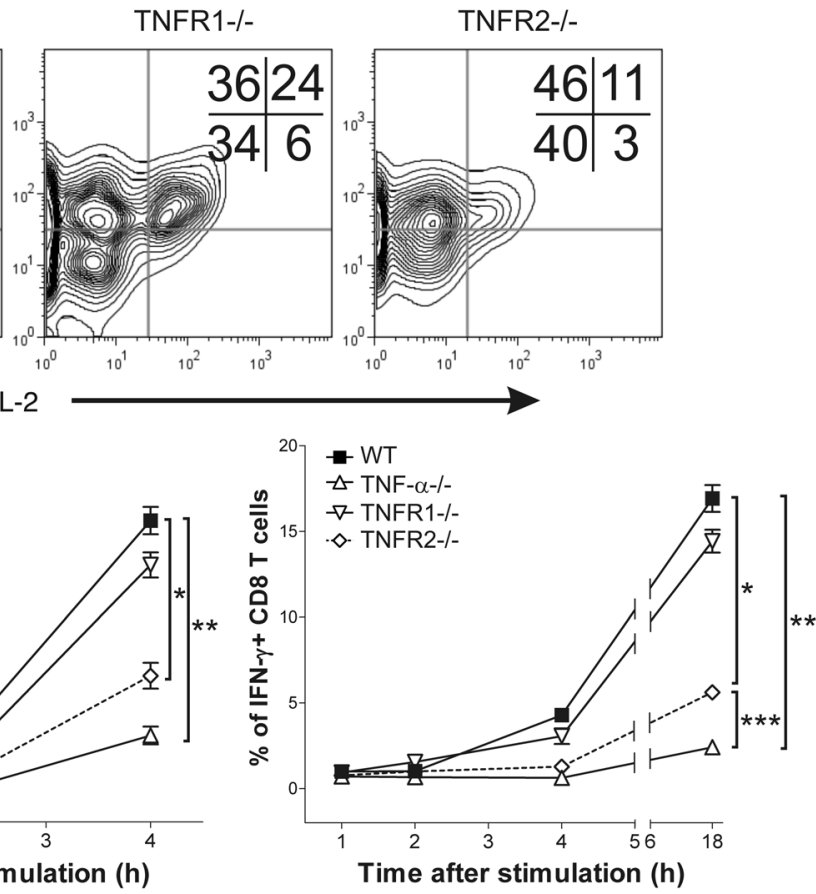

Figure 4

TNF- $\alpha$ /TNFR2-related T cell-intrinsic defects result in defective cytokine production. (A) P14 WT, P14/TNFR1--- P14/TNFR2--, or P14/TNF- $\alpha^{-/-}$ $\mathrm{CD}^{+} \mathrm{T}$ cells were cocultured with GP33-pulsed thioglycollate-induced macrophages for 4 hours in the presence of an inhibitor of intracellular protein transport. Following incubation, P14 cells were harvested, and the levels of intracellular TNF- $\alpha$, IL-2, and IFN- $\gamma$ were evaluated by intracellular flow cytometry. Representative contour plots for IL-2 and TNF- $\alpha$ are shown. The proportion of cells in each quadrant is also indicated. (B) Kinetics of TNF- $\alpha$, IL-2, and IFN- $\gamma$ production by P14 WT, P14/TNFR1 $1^{--}$, P14/TNFR2--- or P14/TNF- $\alpha^{-1-}$ CD8 ${ }^{+}$T cells stimulated as described in A. Mean values \pm SEM from 4 independent experiments are shown. Statistically significant differences at 4 hours are indicated. For TNF- $\alpha,{ }^{*} P=0.0249,{ }^{* *} P=0.0001$. For IL-2, ${ }^{*} P=0.0048,{ }^{*} P=0.0273$. For IFN- $\gamma,{ }^{*} P=0.0122,{ }^{* *} P<0.0001,{ }^{* * *} P=0.0003$.

reduction in the proportion of proliferating P14/TNFR2-/- CD8 ${ }^{+}$ $\mathrm{T}$ cells. Collectively, these data indicate that activation of TNFR2 on $\mathrm{CD}^{+} \mathrm{T}$ cells sustains the early proliferative phase of GP-specific P14 CD8 ${ }^{+} \mathrm{T}$ cells in the tumor-draining $\mathrm{LN}$.

TNFR1 expression on host cells is required for efficient priming of P14 cells in the tumor-draining $L N$. The reduced efficiency of $\mathrm{T}$ cell priming observed in RIP(GP $\times$ Tag2)/TNF- $\alpha^{-/}$hosts (Figure 2) suggests that in addition to the cell-autonomous defect observed in TNF- $\alpha^{-/-}$ $\mathrm{T}$ cells, TNF- $\alpha$ synthesis by cross-presenting APCs in PDLN may be required for the optimal stimulation of $\mathrm{P} 14 \mathrm{CD}^{+} \mathrm{T}$ cells. Alternatively, as TNF- $\alpha$ can induce DC maturation and migration (10, $11,51-55)$, it is possible that undefined host cells produce TNF- $\alpha$ in response to tumor growth and promote maturation and/or accumulation of cross-presenting APCs in the tumor-draining LN, thus favoring the priming of GP-specific $\mathrm{CD}^{+} \mathrm{T}$ cells. To address this latter possibility and to define the relative importance of TNFR1 and TNFR2 in host cells, we adoptively transferred CFSElabeled P14 WT CD8 ${ }^{+} \mathrm{T}$ cells into tumor-bearing TNFR1-- or TNFR2 ${ }^{-/-}$RIP(GP $\times$Tag2) animals. Interestingly, the absence of TNFR1, but not TNFR2, in tumor-bearing hosts resulted in a significant reduction in the proportion of proliferating P14 cells in PDLN (Figure 3D). These data suggest that TNFR1-mediated effects on host cells favor the generation of efficient cross-presenting APCs in response to tumor growth.

Autocrine TNF- $\alpha / T N F R 2$ interaction on T cells promotes optimal cytokine production. Next, we assessed the consequences of impaired
TNF- $\alpha$ signaling during the early phase of $\mathrm{T}$ cell activation. P14 $\mathrm{CD}^{+} \mathrm{T}$ cells isolated from WT, TNF- $\alpha^{-/-}$, TNFR1 $1^{-/}$, or TNFR2 ${ }^{-/-}$ mice were cocultured in the presence of GP33-pulsed, thioglycollate-induced WT macrophages together with an inhibitor of intracellular protein transport. The kinetics of intracellular cytokine production (i.e. TNF- $\alpha$, IL-2, and IFN- $\gamma$ ) by P14 cells was then analyzed by flow cytometry. As shown in Figure 4, TNF- $\alpha^{-/-}$ $\mathrm{T}$ cells displayed severely impaired IL-2 and IFN- $\gamma$ production. Consistent with our in vivo data, IL-2 and IFN- $\gamma$ levels were also reduced in P14/TNFR2 -/- cells, while P14/TNFR1 ${ }^{-/}$and P14 WT cells produced similar amounts of cytokine. No defects in TNF- $\alpha$ synthesis were observed in TNFR $1^{-/}$cells, while a limited but significant decrease was detected in TNFR2 $-/$ P14 cells. Interestingly, TNF- $\alpha$ was the first cytokine produced by T cells, and it was detected as early as 1 hour after activation. Similar data were obtained when TNF- $\alpha^{-/}$thioglycollate-induced macrophages were used to stimulate $\mathrm{P} 14 \mathrm{CD} 8^{+} \mathrm{T}$ cells (data not shown). These data suggest that TNF- $\alpha$ production by $\mathrm{T}$ cells and the subsequent autocrine/ paracrine triggering of TNFR2 are necessary for the optimal production of IL-2 and IFN- $\gamma$.

TNF- $\alpha / T N F R 1$ interactions improve APC maturation. To evaluate the role of TNF- $\alpha$ and its receptors on APC maturation, bone marrow-derived macrophages of the indicated genotypes were treated with IFN- $\gamma$, TNF- $\alpha$, or LPS for 20 hours, and the upregulation of CD40 and CD86 costimulatory molecules was assessed by flow cytometry. As shown in Figure 5, TNF- $\alpha^{-/-}$and TNFR1- ${ }^{--}$, but not 

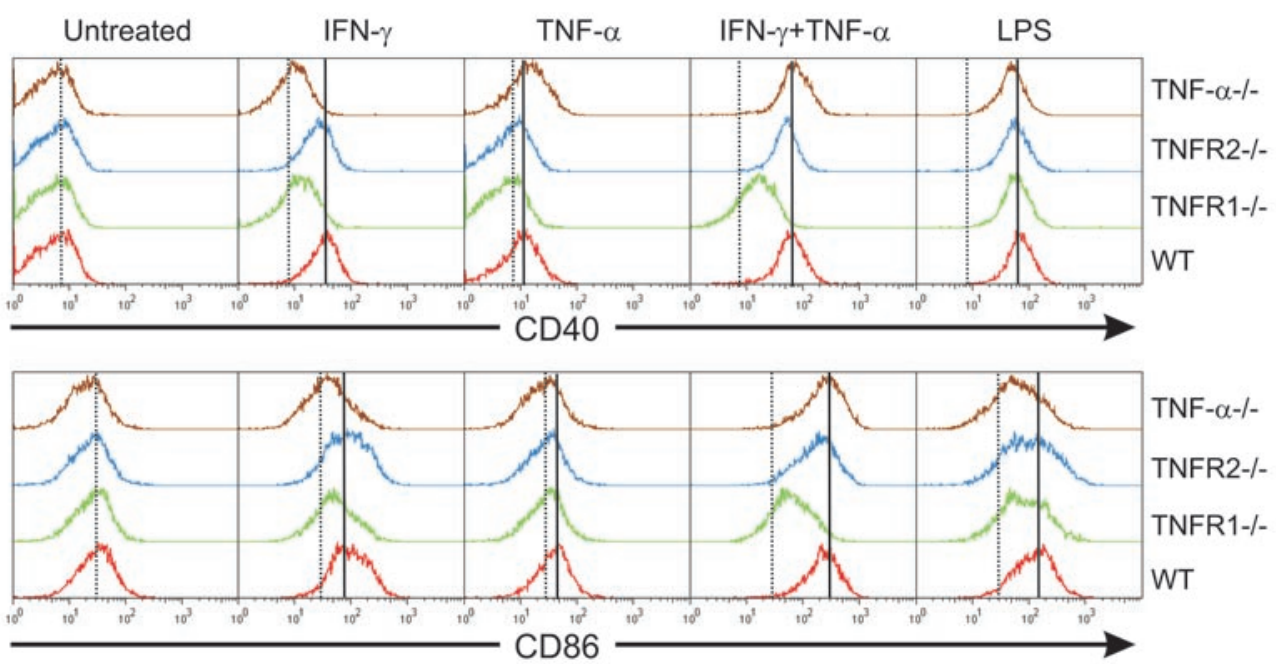

\section{Figure 5}

TNF- $\alpha$ and TNFR1 on APCs are required for optimal activation in response to inflammatory cytokines. Bone marrow-derived macrophages were generated from mice of the indicated genotypes and treated for 20 hours with IFN- $\gamma$, TNF- $\alpha$, or LPS. The levels of CD40 and CD86 expression were then evaluated by flow cytometry. Data are representative of 2 independent experiments.
TNFR2-/-, macrophages displayed a defective upregulation of markers in response to IFN- $\gamma$ but not LPS. When combined with IFN- $\gamma$, TNF- $\alpha$ synergistically upregulated CD40 and CD86 in WT macrophages. Exogenous TNF- $\alpha$ rescued the defect in TNF- $\alpha^{-/-}$ but not in TNFR1 $1^{-/-}$APCs. A similar TNF- $\alpha /$ TNFR1-dependent upregulation of CD40 in response to IFN- $\gamma$ and TNF- $\alpha$ was also observed on bone marrow-derived DCs (data not shown).

Overall, these data show that TNF- $\alpha$ - and TNFR1-mediated signals are required for the optimal maturation of APCs in response to inflammatory cytokines. This suggests that the reduced P14 T cell priming observed in vivo in $\mathrm{RIP}(\mathrm{GP} \times \mathrm{Tag} 2) / \mathrm{TNFR}^{-/-}$mice (Figure $3 \mathrm{D}$ ) could be the result of defective APC maturation.

Impaired tumor immune surveillance in the absence of TNF- $\alpha$. Our data suggest that TNF- $\alpha$ is a critical molecule that promotes tumor immune surveillance in vivo. To further examine the role of TNF- $\alpha$, tumor progression was monitored in WT and TNF- $\alpha^{-/-}$ animals. We previously reported that GP-specific $\mathrm{P} 14 \mathrm{CD}^{+} \mathrm{T}$ cells are spontaneously activated as a result of increased cross-presentation of tumor-derived GP antigen in PDLN in P14/RIP(GP $\times$ Tag2) animals. $\mathrm{CD}^{+} \mathrm{T}$ cells subsequently infiltrate and attack pancreatic tumors, causing a delay in tumor progression (50). $\beta$ Islet cell tumors secrete insulin, and as the tumor mass increases, mice become progressively hypoglycemic; therefore, the effectiveness of the antitumor response can be followed by monitoring blood glucose levels. We assessed the age at onset of hypoglycemia as a marker of tumor development, progression, and immune surveillance in P14/RIP(GP $\times$ Tag2 $) /$ TNF- $\alpha^{-/-}$mice and control animals. As expected, $\mathrm{P} 14 / \mathrm{RIP}(\mathrm{GP} \times \mathrm{Tag} 2) / \mathrm{TNF}-\alpha^{-/-}$mice showed a significant reduction in the age at onset of hypoglycemia when compared with P14 WT/RIP $(\mathrm{GP} \times \mathrm{Tag} 2)$ mice (Figure $6 \mathrm{~A})$. This supports the idea that TNF- $\alpha$ plays a critical role in promoting an immune response to self/tumor-associated antigens.

Consistent with our findings that TNF- $\alpha$ critically regulates the expansion of GP-specific CD8 ${ }^{+} \mathrm{T}$ cells in tumor-draining LN (Figures 2 and 3), the expression of activation markers on GP-specific $\mathrm{CD}^{+} \mathrm{T}$ cells and the expansion of these cells were significantly reduced in PDLN from P14/RIP(GP $\times$ Tag2)/TNF- $\alpha^{-/-}$mice (Figure $6, \mathrm{~B}-\mathrm{D})$. Interestingly, the upregulation of CD69 expression in the TNF- $\alpha^{-/}$hosts suggests that the GP-specific T cells are able to detect antigen but are unable to become effectively activated and as a consequence do not upregulate CD44. In agreement with the defective expansion of GP-specific $\mathrm{CD}^{+} \mathrm{T}$ cells, the number of $\mathrm{CD}^{+} \mathrm{T}$ cells infiltrating the pancreas of P14/RIP(GP $\times$ Tag2)/ TNF- $\alpha^{-/-}$tumor-bearing mice was significantly reduced (Figure $6 \mathrm{E})$. In contrast, pancreatic $\mathrm{CD}^{+}$and $\mathrm{B} 220^{+}$cell numbers were marginally reduced in TNF- $\alpha^{-/-}$animals, but the differences were not statistically significant.

TNF- $\alpha$ has been shown under different conditions to either positively or negatively affect the progression of certain tumors (56-58). In order to assess whether the lack of endogenous TNF- $\alpha$ resulted in a faster or slower development of insulinomas, we recorded the age at which RIP-Tag2 WT, RIP-Tag2/TNF- $\alpha^{+/-}$, and RIP-Tag2/TNF- $\alpha^{-/-}$mice became hypoglycemic. No differences were observed between the different experimental groups (Figure 6A). Since RIP-Tag2 mice do not mount a major antitumor response and because the age at onset of hypoglycemia directly correlates with the extent of tumor growth, these data suggest that endogenous TNF- $\alpha$ does not play any major role in the progression of Tag-induced insulinomas. Moreover, no differences in tumor size or distribution were observed between WT or TNF- $\alpha^{-/-}$ tumor-bearing mice (Supplemental Figure 2). Thus, the early onset of hypoglycemia in the $\mathrm{P} 14 / \mathrm{RIP}(\mathrm{GP} \times \mathrm{Tag} 2) / \mathrm{TNF}^{-\alpha^{-/}}$mice is most likely due to impaired immune surveillance rather than a direct effect of TNF- $\alpha$ on tumor growth.

Collectively, these data indicate that in the absence of TNF- $\alpha$, $\mathrm{T}$ cell priming and expansion in the tumor-draining $\mathrm{LN}$ are impaired, resulting in abrogated antitumor immunity. However, defective recruitment to the tumor site may also play a role.

Recruitment of GP-specific $C D 8^{+}$T cells to the tumor site is TNFR1 dependent. A critical step in the recruitment of activated lymphocytes to the tumor site is the extravasation from the bloodstream to the target tissue. Under inflammatory conditions the upregulation of adhesion molecules such as VCAM-1 on the local vasculature is known to facilitate this process (59). Previous studies reported a predominant role of TNFR1 in the upregulation of multiple adhesion molecules on human endothelial cells or on the vasculature of several murine tissues (60-62). We assessed whether the same was valid for the pancreatic endothelial cells. As shown in Figure 7A, VCAM-1 upregulation in response to recombinant TNF- $\alpha$ injection was rapidly observed on pancreatic vessels from WT, TNF- $\alpha$, and TNFR2 $2^{-/}$animals. In contrast, no upregulation occurred on vessels of TNFR1-/- mice. In light of this observation, we next 


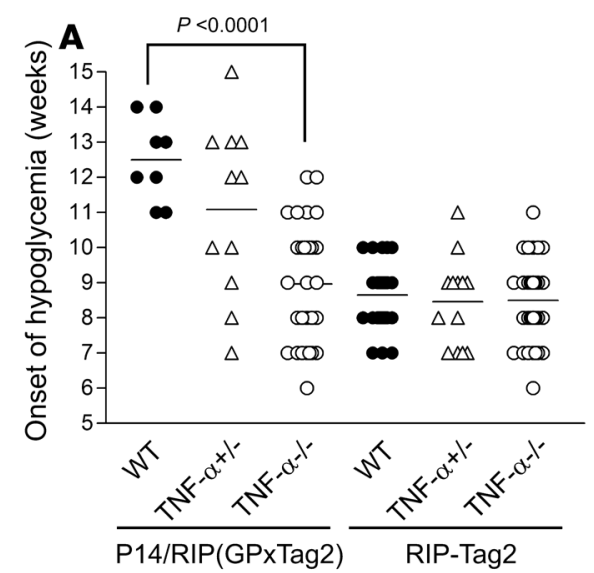

B
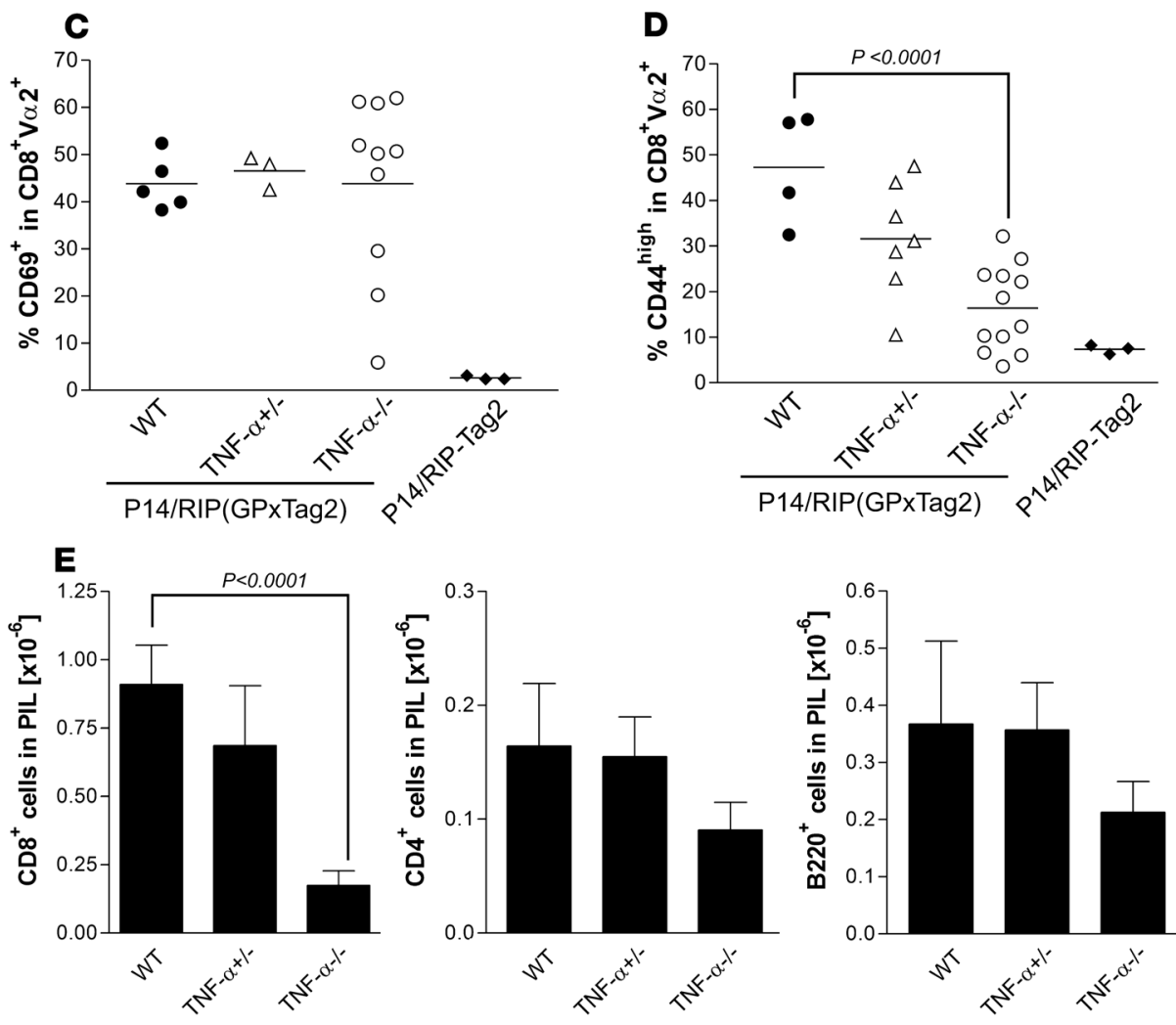

Figure 6

Reduced T cell expansion and tumor infiltration in P14/RIP(GP $\times$ Tag2)/TNF- $\alpha^{-1-}$ animals. (A) Impaired immune surveillance in TNF- $\alpha^{-1-}$ P14/RIP(GP $\times$ Tag2) animals. The age at onset of hypoglycemia was determined by weekly measurement of blood glucose levels in mice of the indicated genotype. This was used as a surrogate marker of tumor development and immune surveillance, since it is a direct measure of $\beta$ islet cell mass. Results obtained for individual mice are shown. Differences between WT and TNF- $\alpha^{-/-}$P14/RIP(GP $\times$Tag2) animals were statistically significant $(P<0.0001)$. (B) The number of $C D 8^{+} \mathrm{V}_{\alpha 2}+\mathrm{P} 14$ cells in PDLN of P14/RIP(GP $\times$ Tag2) animals of the indicated genotypes was calculated after flow cytometry analysis of PDLN. Averages and data obtained from individual mice are shown. Differences between WT and TNF- $\alpha^{-/-}$animals were statistically significant $(P=0.0002)$. (C and $\mathbf{D})$ The proportion of GP-specific P14 CD8 ${ }^{+} \mathrm{T}$ cells expressing high levels of the activation markers CD69 (C) and CD44 (D) was assessed in PDLN after gating on $\mathrm{CD}^{+} \mathrm{V} \alpha 2^{+}$cells. Averages and data obtained from individual mice are shown. iLN data are also shown as a control. Differences between WT and TNF- $\alpha^{-1-}$ animals were statistically significant for CD44 $(P<0.0001)$. (E) Pancreas-infiltrating leukocytes (PIL) were isolated from P14/RIP (GP $\times$ Tag2) WT, TNF- $\alpha^{+/-}$, or $\mathrm{TNF}-\alpha^{-/-}$pancreas, and the number of infiltrating $\mathrm{CD}^{+}, \mathrm{CD}^{+}$, and $\mathrm{B}_{2} 2 \mathrm{O}^{+}$cells was determined by flow cytometry and analysis of the leukocytic infiltrates. Error bars indicate SEM. The number of CD8 ${ }^{+}$ cells in PILs from P14/RIP(GP $\times$ Tag2)/TNF- $\alpha^{-/-}$mice was significantly lower than in those from P14 WT/RIP(GP $\times$ Tag2) animals $(P<0.0001)$ (WT mice: $n=5$; TNF- $\alpha^{-/-}$mice: $\left.n=10\right)$. assessed whether recruitment of GPspecific $\mathrm{P} 14 \mathrm{CD}^{+} \mathrm{T}$ cells to the tumor site was impaired in P14/RIP(GP $\times$ Tag2)/TNFR1 ${ }^{-/-}$animals. In spite of an obvious expansion and activation of GP-specific P14 CD8 ${ }^{+} \mathrm{T}$ cells in PDLN (Figure 7B), no $\mathrm{CD}^{+} \mathrm{T}$ cell infiltration was observed in the pancreas of the same mice (Figure 7C). Overall, these data strongly suggest that the TNFR1-dependent upregulation of adhesion molecules on pancreatic vessels in responses to tumor outgrowth is required for the efficient recruitment of tumor-specific $\mathrm{CD}^{+} \mathrm{T}$ cells to the tumor site.

In vivo CD40 and TLR triggering rescues defective proliferation of $\mathrm{P} 14 / \mathrm{TNF}-\alpha^{-/-} \mathrm{T}$ cells in PDLN of RIP $(\mathrm{GP} \times \mathrm{Tag} 2) / \mathrm{TNF}^{-/}$ mice. Based on the data presented above, we hypothesized that multiple immunostimulatory parameters provided during LCMV infection (systemic and extensive antigen presentation, TLR triggering, CD4 help, costimulation, and systemic cytokine secretion) may be insufficient or lacking in tumor-bearing animals. These factors likely cooperate and optimally activate $\mathrm{T}$ cells, thus rendering TNF$\alpha$ dispensable. Therefore, we assessed whether exogenous provision of such factors would be able to rescue the defective proliferation of P14/TNF- $\alpha^{-/-}$ $\mathrm{T}$ cells in $\mathrm{RIP}(\mathrm{GP} \times \mathrm{Tag} 2) / \mathrm{TNF}-\alpha^{-/-}$ tumor-bearing mice. We adoptively transferred CFSE-labeled P14 WT or TNF- $\alpha^{-/-}$into WT or TNF- $\alpha^{-/-}$ $\mathrm{RIP}(\mathrm{GP} \times \mathrm{Tag} 2)$ mice and simultaneously administered i.v. agonistic CD40 $\mathrm{Ab}$ with or without the TLR2 ligand Pam3Cys-SKKKK (Pam3). As shown in Figure 8, while CD40 triggering only marginally improved the proliferation of P14 WT CD8 ${ }^{+} \mathrm{T}$ cells in WT RIP(GP $\times$ Tag2) mice, it clearly enhanced the proliferation of P14/TNF- $\alpha^{-/-} \mathrm{T}$ cells in PDLN of RIP(GP $\times$ Tag2)/TNF $\alpha^{-/-}$ mice. Moreover, the combination of a CD40 agonist with the triggering of TLR2 by Pam 3 further increased the proportion of dividing cells and the extent to which they proliferated.

These data indicate that CD40, TLR triggering, and/or other similar factors are limiting in our tumor model, making TNF- $\alpha$ indispensable and critical for the activation of tumor-reactive $\mathrm{T}$ cells. Moreover, these data suggest that during a strong viral infection, 


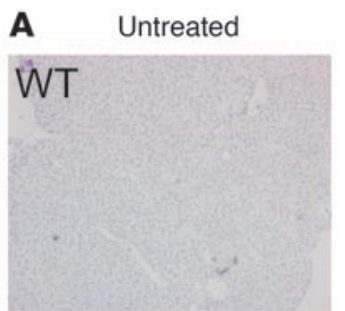

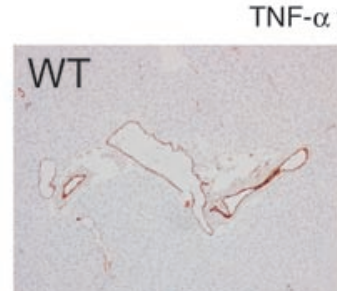

TNF- $\alpha$ treated
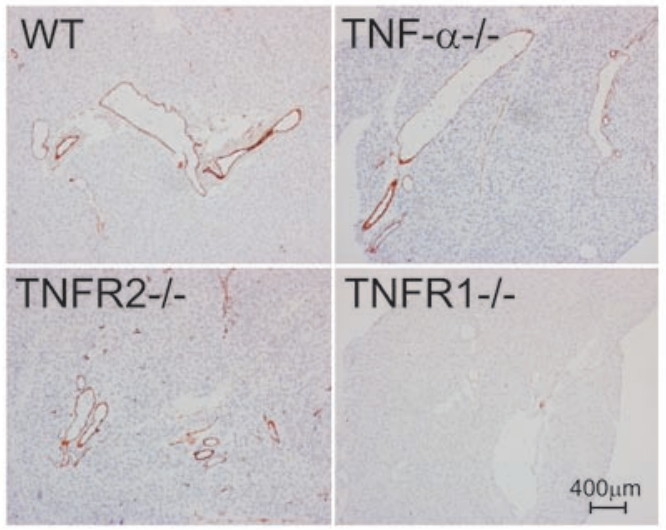

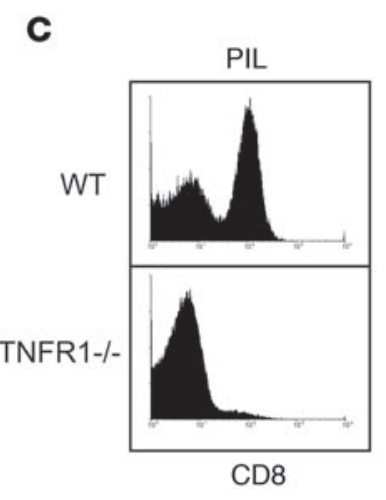

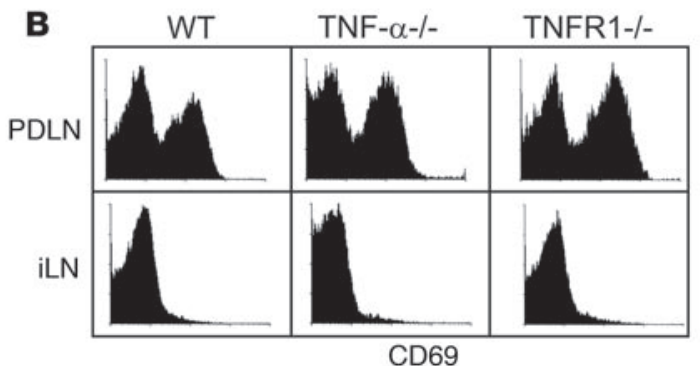

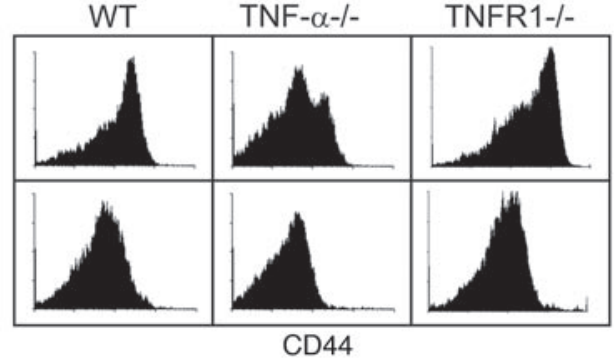

Figure 7

TNFR1 signaling modulates the expression of adhesion molecules on pancreatic vessels and favors recruitment of GP-specific CD8 ${ }^{+} \mathrm{T}$ cells to the tumor site. (A) Histological sections of pancreas from mice of the indicated genotypes were stained for VCAM-1 7 hours following i.p. injection of recombinant mouse TNF- $\alpha$. (B) T cell activation in PDLN of P14/RIP(GP $\times$ Tag2)/TNFR1 $1^{-/}$animals. Comparison of the expression of CD69 and CD44 on $\mathrm{CD}^{+} \mathrm{V} \alpha 2^{+}$cells from PDLN or iLN of WT, TNF- $\alpha^{-/-}$, or TNFR1 $1^{-/} \mathrm{P} 14 / \mathrm{RIP}(\mathrm{GP} \times \mathrm{Tag} 2)$ animals. Representative results from at least 4 independent experiments on different mice are shown. (C) Impaired CD8 ${ }^{+}$T cell recruitment to pancreas of P14/RIP(GP $\times$Tag2)/TNFR1 ${ }^{-/-}$animals. Proportion of CD8 ${ }^{+}$T cells in PILs from WT or TNFR1 ${ }^{-1-}$ animals. A representative result from at least 4 independent mice is shown.

the generation of TLR ligands and other multiple immunostimulatory factors renders the costimulatory functions of TNF- $\alpha$ dispensable during the priming phase of the immune response.

\section{Discussion}

The expression of TNF receptors, the wide range of effects triggered by TNF- $\alpha$, and the diversity and complexity of the experimental systems and disease models have complicated the appreciation of the multiple roles that this cytokine plays in immune processes in vivo. In a progressive disease that involves multiple cellular elements, including DCs, T cells, and vasculature, analysis at a single time point or assessment of a single cellular element does not comprehensively integrate the possible functions of an important cytokine. Furthermore, because of the heterogeneity of immune responses, depending on the inciting antigens and inflammatory reactions, the role of a particular cytokine may be redundant in certain circumstances yet critical in others.

We investigated whether the involvement and relevance of TNF- $\alpha$ in immunity is associated with the immunostimulatory properties of the antigen. This would have major implications for TNF- $\alpha$ 's role in tumor immune surveillance. We used LCMV GP as a model antigen in the context of virus inducing a strong inflammatory response (i.e., LCMV) or a GP-expressing spontaneous tumor as a stimulus associated with limited immunostimulatory capacity (i.e. RIP[GP $\times$ Tag2] mice). Using these models, we were able to show that TNF- $\alpha$ and its receptors are dispensable when an optimal immune response is induced, but they critically regulate multiple aspects of the immune response when the antigen is associated with tumors. An adoptive transfer strategy allowed us to elucidate the operating mechanisms, revealing the complexity by which TNF- $\alpha$ and its receptors regulate different cellular subsets and stages of the immune responses. In particular, we found that under suboptimal immunostimulatory conditions, TNF- $\alpha^{-/-}$animals display multiple T cell-intrinsic and T cell-extrinsic defects, which differentially rely on TNFR1- and TNFR2-mediated signals. These additive and synergistic defects ultimately result in impaired antitumor immunity due to defective activation, proliferation, and recruitment of tumor-specific $\mathrm{CD}^{+} \mathrm{T}$ cells.

We were able to dissect the T cell-intrinsic defect, and we showed that the autocrine/paracrine production of TNF- $\alpha$ by tumor-specific $\mathrm{CD}^{+} \mathrm{T}$ cells in vivo is important in sustaining $\mathrm{T}$ cell expansion. Our data support a more critical role for TNFR2 as the major transducer of such costimulatory signals. In agreement with a previous report (63), we found that TNF- $\alpha$ production occurred as early as 1 hour following $\mathrm{T}$ cell activation and preceded IL-2 and IFN- $\gamma$ release. Importantly, TNF- $\alpha$ release and activation of TNFR2 affected the efficiency of T cell cytokine production and proliferation. The critical role of TNF- $\alpha$ and TNFR 2 in inducing and potentiating early $\mathrm{T}$ cell activation is consistent with previous in vitro (37-44) and in vivo studies (45). TNFR2 has been reported 


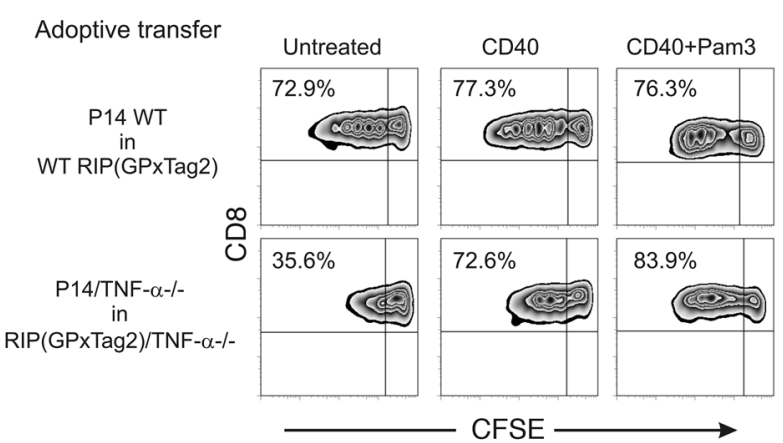

Figure 8

The exogenous administration of immunostimulatory factors rescues the proliferation of P14/TNF- $\alpha^{-/}$T cells in PDLN of RIP(GP $\times$Tag2)/ TNF- $\alpha^{-1-}$ mice. CFSE-labeled naive P14 WT or P14/TNF- $\alpha^{-/}$CD8 ${ }^{+} \mathrm{T}$ cells were adoptively transferred into the indicated RIP $(\mathrm{GP} \times \mathrm{Tag} 2)$ hosts in combination with CD40 agonistic Ab or CD40 Ab and the TLR2 ligand Pam3. Proliferation of CFSE-labeled cells was assessed 3 days later in PDLN. Zebra plots were gated on $\mathrm{CFSE}^{+} \mathrm{CD} 8^{+} \mathrm{V} \alpha 2^{+}$ cells. The percentage in each plot indicates the proportion of dividing cells among the CFSE-labeled population. The data presented are representative of 3 independent experiments.

to lower the threshold of $\mathrm{T}$ cell activation in vitro by providing synergistic signals, along with CD28 costimulation, that result in the optimal upregulation of CD25, IL-2, IFN- $\gamma$, and TNF- $\alpha$ production $(39,40)$. Consequently, $\mathrm{T}$ cell proliferation and survival are greatly enhanced $(39,40)$. The pivotal role of TNFR2 is further substantiated by the fact that this is the principal TNF receptor expressed on the surface of naive P14 T cells and T cells in the early phase of activation. Although TNFR1 was reported to facilitate $\mathrm{T}$ cell proliferation in allogeneic models $(64,65)$, its deficiency in $\mathrm{T}$ cells did not substantially affect $\mathrm{CD}^{+} \mathrm{T}$ cell activation in our models. Therefore, the disruption of TNF- $\alpha$ /TNFR2-mediated signals likely explains the $\mathrm{T}$ cell-intrinsic defect observed in our system.

While TNF- $\alpha$ and TNFR2 deficiency in P14 T cells only partially affected $\mathrm{T}$ cell proliferation in vivo, priming and expansion of $\mathrm{P} 14$ $\mathrm{T}$ cells were almost completely abolished when non- $\mathrm{T}$ cell populations were also unable to produce TNF- $\alpha$. Optimal T cell activation requires the upregulation of costimulatory molecules (e.g., CD40 and CD86) on professional APCs. This maturation process is triggered by exogenous or endogenous danger signals produced in response to certain threats $(66,67)$. Interestingly, in view of its capacity to modulate DC maturation and migration (10, 11, 51-55), TNF- $\alpha$ represents a candidate endogenous danger factor that may be released in responses to tumor growth and that may potentially promote this critical maturation process. Previous studies have shown that the LCMV GP tissue-specific antigen is cross-presented on bone marrow-derived APCs (50). Our adoptive transfer experiments in TNF- $\alpha^{-/-}$tumor-bearing mice suggested that endogenous TNF- $\alpha$ directly or indirectly affected the capacity of cross-presenting APCs to efficiently prime and stimulate GP-specific CD8 ${ }^{+} \mathrm{T}$ cells. Our in vitro experiments using bone marrow-derived macrophages or DCs allowed us to establish that an autocrine/paracrine TNF- $\alpha$ / TNFR1 loop was also critical for the optimal upregulation of not only CD40 but also CD86 costimulatory molecules in response to inflammatory cytokines such as IFN- $\gamma$. These findings extend previous studies $(68,69)$ and suggest that TNF- $\alpha^{-/-}$and TNFR1 $1^{-/}$APCs have an impairment in the ability to mature in response to limited or suboptimal inflammatory conditions such as those encountered in the context of spontaneously growing malignancies. However, we cannot rule out the possibility that TNF- $\alpha /$ TNFR 1 interactions might also be required for the migration/recruitment of APCs from the tumor site to the draining LN.

Our results also suggest that, besides affecting APC maturation, TNF- $\alpha$ and TNFR 1 are also critically required for the upregulation of adhesion molecules such as VCAM-1 on pancreatic vessels. As a consequence, in the absence of TNFR1, GP-specific $\mathrm{CD}^{+} \mathrm{T}$ cells primed in the PDLN could not properly home to the tumor. In view of the severely impaired tumor infiltration in TNF- $\alpha^{-/-}$or TNFR1 $1^{-1-}$ P14/RIP(GP $\times$ Tag2) mice, we were unable to assess whether TNF- $\alpha$ also plays a role at the effector stage of the antitumor response. As TNF- $\alpha$ and IFN- $\gamma$ have been suggested to be involved in the destruction of $\beta$ cells in autoimmune diabetes (70), it will be interesting to assess whether the same is valid in the case of $\beta$ islet cell tumors.

We also investigated the role of endogenous TNF- $\alpha$ on tumor progression. Endogenous TNF- $\alpha$ has been implicated in tumor development following the application of cancer-promoting agents to the skin $(56,57)$. This potential pro-oncogenic activity has been attributed to multiple downstream inflammatory products generated in response to TNF- $\alpha$ that may directly or indirectly promote cellular transformation and tumor growth and spread (71-75). Recent studies provide some experimental evidence linking inflammation and cancer. TNF- $\alpha$, its cognate receptors, and the downstream NF- $\mathrm{kB}$ signaling pathway may play a role in this process (76-79). Our results indicate that endogenous TNF- $\alpha$ does not have any direct effect on Tag-induced $\beta$ cell tumor development or progression in this model. The nature of the oncogenic transformation, the degree and chronicity of inflammation, and perhaps organ specificity and sensitivity may all modulate the potential importance of inflammation on tumor development and progression, as may the oncogenic potential of the infectious agents that initiate the inflammatory response. Contrary to reports in the literature implicating TNF- $\alpha$ in tumor progression in mouse models, the use of TNF- $\alpha$ antagonists in patients with inflammatory arthritis has been associated with an increased risk of malignancy (46). Our data provide a plausible explanation for this apparent association.

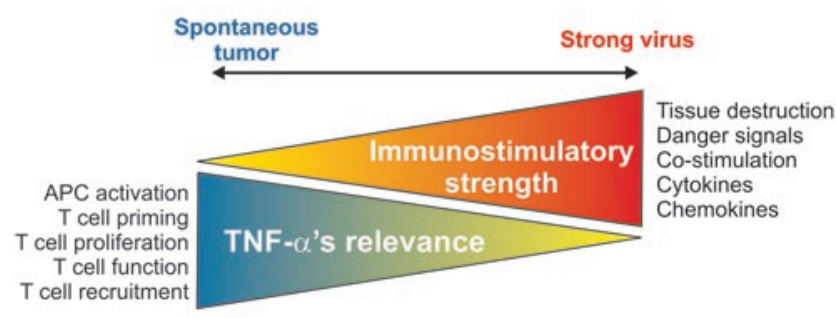

\section{Figure 9}

Model depicting the inverse association between immunostimulatory strength and inflammation and the requirement for TNF- $\alpha$ in T cell immune responses. In conditions when T cells are activated in the presence of optimal stimulation (optimal APC maturation by danger signals, costimulation, cytokines, etc.), TNF- $\alpha$ is totally or partially dispensable for $\mathrm{T}$ cell activation (e.g., systemic viral infection), while when such factors become limiting (e.g., spontaneous tumor growth), TNF- $\alpha$ 's roles become relevant and critical at multiple levels of the T cell immune response. 
Our in vivo model provides clear evidence for a pivotal role of endogenous TNF- $\alpha$, TNFR1, and TNFR2 in the priming and subsequent phases of an effective primary $\mathrm{CD}^{+} \mathrm{T}$ cell immune response against poorly immunogenic tumors. We identified TNFR2 as a pivotal molecule required for optimal $\mathrm{T}$ cell activation and TNFR1 as a critical element mediating the phenotypic and functional maturation of APCs in response to inflammatory cytokines. We provide evidence that TNFR1 triggering on the tumor vasculature is critical for the upregulation of adhesion molecules required for the recruitment of tumor-specific $\mathrm{CD}^{+} \mathrm{T}$ cells to the tumor site. In contrast, these factors appear to be dispensable during a strong viral response. Indeed, the kinetics of autoimmune diabetes development following LCMV infection were identical in TNF- $\alpha^{-/}$ RIP-GP and P14/RIP-GP mice. This observation clearly indicates that GP-specific $\mathrm{CD}^{+} \mathrm{T}$ cell responses initiated by different triggering events may rely on different sets of factors.

The lack of endogenous TNF- $\alpha$ did not prevent the efficient expansion of LCMV GP- or nucleoprotein-specific (NP-specific) $\mathrm{CD}^{+} \mathrm{T}$ cells in response to LCMV (Supplemental Figure 1). Rather, we observed increased numbers of GP33-, GP276-, and NP396specific T cells in the spleen of TNF- $\alpha^{-/-}$mice at day 15 after LCMV infection. The increased number of LCMV-specific CD8 ${ }^{+} \mathrm{T}$ cells in TNF- $\alpha^{-/}$infected mice that we observed was only modest compared with those reported in LCMV-infected TNFR1/TNFR2 double-deficient mice (34). Perhaps this discrepancy is due to the additional defect in lymphotoxin $\alpha$ signaling in TNFR1/TNFR2deficient animals. Alternatively, the lower dose of LCMV used to infect animals in our study may contribute to the differences. The exact reasons for and relevance of the increased number of LCMVspecific $\mathrm{CD}^{+} \mathrm{T}$ cells in mice characterized by the constitutive lack of TNF- $\alpha$ or TNF receptor signaling are unclear. We are currently investigating several possibilities in order to clarify this issue.

Regardless of whether $T$ cell expansion following infection of TNF- $\alpha$ - and TNFR-deficient mice is equivalent or marginally enhanced compared with WT mice, it is clear that the innate response following LCMV infection certainly provides a more robust inflammatory milieu than that generated by the outgrowth of spontaneous pancreatic tumors. Virus-associated systemic danger and inflammatory signals likely promote DC maturation events that allow normal $\mathrm{T}$ cell expansion even in the absence of TNF- $\alpha$. Our data are consistent with observations that TNFR $1^{-/-}$or TNFR2-/- animals show no or only minor defects following LCMV infection $(25,31,34)$. Of note, the requirement for CD28 costimulation is not absolute either, as efficient $\mathrm{T}$ cell immune responses against LCMV can be induced in CD28-/- animals (80). This suggests that prolonged TCR triggering or virus-related signals and inflammation can overcome the need for early costimulatory molecules such as CD28 and TNF- $\alpha$. Costimulation by other members of the CD28 or TNF receptor superfamilies (e.g., ICOS, CD40, OX40, and 4-1BB) and their cognate ligands might be involved. In addition, other inflammatory factors endowed with TNF- $\alpha$-like properties, for example IL-1 and IL-6, may induce OX40 expression on T cells and promote $\mathrm{T}$ cell survival in the absence of CD28 $(81,82)$. In support of our hypothesis that alternative and multiple immunostimulatory factors may render TNF- $\alpha$ dispensable for $\mathrm{T}$ cell activation, we found that the exogenous application of a CD40 agonistic Ab and the TLR2 ligand Pam3 was sufficient to rescue the defective priming and proliferation of $\mathrm{P} 14 / \mathrm{TNF}-\alpha^{-/-}$in response to tumor-derived antigens in $\mathrm{RIP}(\mathrm{GP} \times \mathrm{Tag} 2) / \mathrm{TNF}-\alpha^{-/-}$ mice. This suggests that the defective activation of GP-specific P14
$\mathrm{T}$ cells in tumor-bearing mice is due to the lack multiple signals that enhance APC maturation and T cell activation. Under such suboptimal stimulatory conditions, TNF- $\alpha$ production by multiple cell types becomes critical in the $\mathrm{T}$ cell priming process. Therefore, it is likely that CD40 triggering (provided by either CD4 ${ }^{+}$ T cells or NK cells), TLR triggering, and potentially other signaling events are major limiting factors in our tumor model that render TNF- $\alpha$ critical for the activation of tumor-reactive T cells. While reduced antigen presentation might still be a critical element to consider, these results demonstrate that if APCs and T cells are optimally activated by multiple costimulatory factors and danger signals (a condition amply satisfied by LCMV infection), extensive proliferation of $\mathrm{T}$ cells can still occur in the presence of reduced amounts of antigen and in the absence of TNF- $\alpha$.

In view of these findings, we propose that TNF- $\alpha$ and its receptors are involved in the modulation of multiple phases of a $\mathrm{T}$ cell immune response. However, in conditions of a strong inciting stimulus, these roles can be eclipsed by other redundant factors endowed with similar functions (Figure 9). On the other hand, in physiological and pathological cases of suboptimal stimuli, triggering, and inflammation - for example, tumor growth - TNF- $\alpha$ is a critical in the immune response. Based on these data, it is possible to reconcile the discrepancies in the literature regarding the role of TNF- $\alpha$ in T cell immunity depending on the experimental system and the nature and strength of the stimulus triggering the immune response.

In conclusion, we demonstrated that in conditions of limited immunostimulatory capacity such as during the development of spontaneous malignancies, the disruption of TNF- $\alpha /$ TNFR2 feedback on T cells and TNF- $\alpha$ /TNFR 1 feedback on accessory cells substantially impairs tumor immune surveillance. Our results may have important implications for the use of TNF- $\alpha$ antagonists in autoimmune or cancer patients and their potential sequelae at the level of tumor development or progression.

\section{Methods}

Mice and tumor monitoring. C57BL/ 6 WT mice and gene targeted TNF- $\alpha-$ deficient (TNF- $\alpha^{-/}$), TNFR1-deficient (TNFR1 $1^{-/}$), and TNFR2-deficient (TNFR2-/-) animals were purchased from The Jackson Laboratory (Tnftm1Gkl, Tnfrsf $1 a^{\text {tm } 1 M a k}$, and Tnfrsf $1 b^{\text {tmIMwm }}$, respectively). These mice were interbred with P14 (83), RIP-GP (47), and RIP-Tag2 mice (48). The majority of CD8 ${ }^{+}$ $\mathrm{T}$ cells in P14 TCR transgenic mice express a V $\alpha 2 V \beta 8.1$ TCR specific for the H-2D ${ }^{b}$-restricted GP33 epitope of LCMV GP (83). Blood glucose levels of mice bearing the RIP-Tag2 transgene were measured weekly, starting from 6 weeks of age, and all the experiments were performed on mice with 2 consecutive hypoglycemic readings (i.e., blood glucose levels below $5 \mathrm{mM}$ ). An i.v. dose of 3,000 PFU LCMV Arm was used to infect RIP-GP and C57BL/6 mice. A dose of $5 \times 10^{5}$ PFU LCMV Arm was used to infect P14/RIP-GP mice. All animal experiments were approved by the animal ethics committee, University Health Network, Toronto, Ontario, Canada.

Adoptive transfers, CFSE labeling. For the adoptive transfer of naive P14 $\mathrm{CD}^{+} \mathrm{T}$ cells, $\mathrm{CD}^{+} \mathrm{T}$ cells were purified by magnetic separation using the $\mathrm{CD}^{+} \mathrm{T}$ cell isolation kit (negative selection; Miltenyi Biotec). $\mathrm{CD}^{+} \mathrm{T}$ cells were labeled with CFSE as previously described (50) using $5 \mu \mathrm{M}$ CFSE (Molecular Probes; Invitrogen). LCMV-infected animals or tumor-bearing hosts were injected i.v. in the tail vein with $4 \times 10^{6}$ cells, and the extent of $\mathrm{T}$ cell proliferation in the $\mathrm{LN}$ was assessed 3 days later.

Where indicated, $200 \mu \mathrm{g}$ of agonistic anti-CD40 Ab (FGK45; purified rat anti-mouse) and $100 \mu \mathrm{g}$ Pam3 (EMC Microcollections GmbH) were coinjected i.v. with CFSE-labeled P14 cells. 
Isolation of pancreas-infiltrating lymphocytes. Freshly harvested pancreas was rapidly minced in small pieces and subsequently incubated for 30 minutes in HBSS/EDTA $(1.3 \mathrm{mM})$ at $37^{\circ} \mathrm{C}$ with occasional agitation. Following centrifugation, the pieces were resuspended in FCS-free RPMI supplemented with $0.7 \mathrm{mg} / \mathrm{ml}$ Collagenase D (Roche) and $10 \mathrm{U} / \mathrm{ml}$ DNase I (Roche) and further incubated for 1 hour at $37^{\circ} \mathrm{C}$ with frequent agitation. Following collagenase/DNase digestion, the remaining tissue debris was passed through a $70-\mu \mathrm{m}$ cell strainer and centrifuged. The pellet was then resuspended in $5 \mathrm{ml} 44 \%$ Percoll and underlaid with $5 \mathrm{ml}$ 67.5\% Percoll and subsequently spun for 20 minutes at $550 \mathrm{~g}$. Following centrifugation, the enriched leukocyte fraction was collected from the 44\%-67.5\% Percoll interphase (Pharmacia), washed in HBSS supplemented with 5\% FCS, resuspended in medium, and analyzed by flow cytometry as described below.

VCAM-1 induction and immunohistochemistry. Histological analyses and the evaluation of tumor size on histological sections were performed as previously described (50). Activation of endothelial cells and upregulation of VCAM-1 were assessed on pancreatic sections isolated from mice of the indicated genotypes 7 hours after i.p. injection of $5 \mu \mathrm{g}$ recombinant mouse TNF- $\alpha$ (PeproTech) as described previously (62). The $\mathrm{CD} 106 \mathrm{Ab}$ from $\mathrm{BD}$ Biosciences was used for staining according to the manufacturer's protocol.

$T$ cell stimulation and flow cytometry analysis. Thioglycollate-induced macrophages were harvested from the peritoneum of C57BL/ 6 mice 6 days following i.p. injection of $2 \mathrm{ml}$ thioglycollate. Macrophages were subsequently plated at a concentration of $2 \times 10^{5}$ cells/well in a 96-well plate and pulsed for 2 hours at $37^{\circ} \mathrm{C}$ with $10^{-9} \mathrm{M}$ peptide (KAVYNFATM; New England Peptide). After 3 washes to remove excess peptide, $10^{5}$ purified P14 CD8 ${ }^{+}$ $\mathrm{T}$ cells of the indicated genotypes were added to each well in the presence of the intracellular protein transport inhibitor monensin (BD Biosciences Pharmingen). Cells were harvested 1, 2, 4, and 18 hours later, labeled with a CD $8^{+} \mathrm{mAb}$, and subsequently fixed with a $2 \%$ paraformaldehyde solution. Following fixation, cells were permeabilized using the Perm/Wash solution (BD Biosciences - Pharmingen) and subsequently incubated for 30 minutes with mAbs specific for TNF- $\alpha$, IFN- $\gamma$, and IL-2.

The $\mathrm{mAbs}$ specific for the following markers were purchased from eBioscience or BD Biosciences - Pharmingen: CD8, CD4, CD40, CD11b, CD86, B220, V $\alpha 2$, CD69, CD44, IFN- $\gamma$, TNF- $\alpha$, and IL-2. TNFR1- and TNFR2specific $\mathrm{mAbs}$ were obtained from Biolegend. All flow cytometry data were acquired on a FACSCalibur (BD) and analyzed using FlowJo (Tree Star) or WinMDI (http://facs.scripps.edu/software.html).

Tetramers were produced by conjugating monomers, H-2 $\mathrm{D}^{\mathrm{b}} / \mathrm{GP} 33$ (KAVYNFATM), H-2D $/$ GP276 (SGVENPGGYCL), and H-2D b $^{\mathrm{b}} / \mathrm{NP} 396$ (FQPQNGQFI), with Extravidin-PE (Sigma-Aldrich). Monomers were obtained from the Canadian Network for Vaccines and Immunotherapeutics. Cells were stained with tetramers for 1 hour at $4^{\circ} \mathrm{C}$.

Bone marrow-derived macrophages and DC cultures. Bone marrow was harvested from the femur and tibia of mice. For DC cultures, $2 \times 10^{6} \mathrm{red}$ cell-depleted bone marrow cells were plated in Petri dishes in $10 \mathrm{ml}$ complete medium (RPMI, 10\% FCS, glutamine, penicillin/streptomycin, and $\beta$-mercaptoethanol) supplemented with $40 \mathrm{ng} / \mathrm{ml}$ GM-CSF (PeproTech).
After 3 days, $10 \mathrm{ml}$ fresh medium supplemented with GM-CSF was added. At 6 days, half of the culture medium was spun and cells replated in the original dish with $10 \mathrm{ml}$ fresh medium and GM-CSF. On day 7, nonadherent DCs were harvested and $5 \times 10^{5}$ cells $/ \mathrm{ml}$ replated in the presence of LPS $(10 \mathrm{ng} / \mathrm{ml})$, recombinant mouse TNF- $\alpha(10 \mathrm{ng} / \mathrm{ml})$, or IFN- $\gamma(20 \mathrm{ng} / \mathrm{ml})$. After 20 hours, cells were harvested, and CD40 and CD86 expression was analyzed by flow cytometry.

To generate macrophages, single-cell suspensions from red cell-depleted bone marrow were cultured in tissue culture-treated plates for 24 hours in the presence of medium containing $10 \%$ LPS-free FCS and $50 \mathrm{ng} / \mathrm{ml}$ M-CSF (PeproTech) to remove contaminating fibroblast-like stromal cells. Poorly adherent and nonadherent cells were collected and replated on tissue culture-treated plates in the presence of M-CSF and cultured for 3 days to differentiate and expand the macrophage population. After 3 days in culture, nonadherent cells were discarded, and cell dissociation buffer (Gibco; Invitrogen) was used to harvest the adherent macrophage population. Isolated macrophages were cultured at a density of $10^{6}$ cells $/ \mathrm{ml}$ in medium containing M-CSF and the appropriate stimuli described above. Macrophage maturation markers were analyzed by flow cytometry 20 hours later. Both macrophage and DC cultures were more than 95\% pure based on CD11b and CD11c staining, respectively.

Statistics. The significance of observed differences between indicated groups was assessed by an unpaired Student's $t$ test. Tests were 2-tailed, with a confidence interval of $95 \%$. $P$ values $<0.05$ were considered significant. Statistical analyses were performed using Prism software.

\section{Acknowledgments}

We thank Mandana Nikpour for comments and discussion. This work was supported by a Canadian Institutes for Health Research grant to P.S. Ohashi. T. Calzascia was supported by the Boninchi Foundation (Geneva, Switzerland) and is currently a Research Fellow of the Terry Fox Foundation through an award from the National Cancer Institute of Canada. P.S. Ohashi holds a Canada Research Chair in infection and immunity.

Received for publication May 2, 2007, and accepted in revised form September 12, 2007.

Address correspondence to: Pamela S. Ohashi, Campbell Family Institute for Breast Cancer Research, Ontario Cancer Institute, Departments of Medical Biophysics and Immunology, 610 University Avenue, Toronto, Ontario M5G 2M9, Canada. Phone: (416) 9462357; Fax: (416) 946-2086; E-mail: pohashi@uhnres.utoronto.ca.

Laurent Sabbagh's present address is: Department of Immunology, University of Toronto, Toronto, Ontario, Canada.

Nobuyuki Ono's present address is: Department of Clinical Immunology, Rheumatology and Infectious Diseases, Kyushu University Hospital, Fukuoka, Japan.
1. Carswell, E.A., et al. 1975. An endotoxin-induced serum factor that causes necrosis of tumors. Proc. Natl. Acad. Sci. U. S. A. 72:3666-3670.

2. MacEwan, D.J. 2002. TNF receptor subtype signalling: differences and cellular consequences. Cell Signal. 14:477-492.

3. Wajant, H., Pfizenmaier, K., and Scheurich, P. 2003. Tumor necrosis factor signaling. Cell Death Differ. 10:45-65.

4. McDevitt, H., Munson, S., Ettinger, R., and Wu, A. 2002. Multiple roles for tumor necrosis factor- $\alpha$ and lymphotoxin $\alpha / \beta$ in immunity and autoim- munity. Arthritis Res. 4(Suppl. 3):S141-S152.

5. Kollias, G. 2005. TNF pathophysiology in murine models of chronic inflammation and autoimmunity. Semin. Arthritis Rheum. 34:3-6.

6. Deng, G.M., Zheng, L., Chan, F.K., and Lenardo, M. 2005. Amelioration of inflammatory arthritis by targeting the pre-ligand assembly domain of tumor necrosis factor receptors. Nat. Med. 11:1066-1072.

7. Kollias, G., and Kontoyiannis, D. 2002. Role of TNF/TNFR in autoimmunity: specific TNF receptor blockade may be advantageous to anti-TNF treatments. Cytokine Growth Factor Rev. 13:315-321.
8. Choo-Kang, B.S., et al. 2005. TNF-blocking therapies: an alternative mode of action? Trends Immunol. 26:518-522.

9. Kassiotis, G., Kranidioti, K., and Kollias, G. 2001. Defective CD4T cell priming and resistance to experimental autoimmune encephalomyelitis in TNF-deficient mice due to innate immune hyporesponsiveness. J. Neuroimmunol. 119:239-247.

10. Lee, L.F., et al. 2005. The role of TNF- $\alpha$ in the pathogenesis of type 1 diabetes in the nonobese diabetic mouse: analysis of dendritic cell maturation. Proc. Natl. Acad. Sci. U. S. A. 102:15995-16000. 
11. Trevejo, J.M., et al. 2001. TNF- $\alpha$-dependent maturation of local dendritic cells is critical for activating the adaptive immune response to virus infection. Proc. Natl. Acad. Sci. U. S. A. 98:12162-12167.

12. Bromberg, J.S., Chavin, K.D., and Kunkel, S.L. 1992. Anti-tumor necrosis factor antibodies suppress cell-mediated immunity in vivo. J. Immunol. 148:3412-3417.

13. Christen, U., et al. 2001. A dual role for TNF- $\alpha$ in type 1 diabetes: islet-specific expression abrogates the ongoing autoimmune process when induced late but not early during pathogenesis. J. Immunol. 166:7023-7032.

14. Green, E.A., and Flavell, R.A. 2000. The temporal importance of TNFalpha expression in the development of diabetes. Immunity. 12:459-469.

15. Green, E.A., Wong, F.S., Eshima, K., Mora, C., and Flavell, R.A. 2000. Neonatal tumor necrosis factor $\alpha$ promotes diabetes in nonobese diabetic mice by CD154-independent antigen presentation to CD8+ T cells. J. Exp. Med. 191:225-238.

16. Wu, A.J., Hua, H., Munson, S.H., and McDevitt, H.O. 2002. Tumor necrosis factor- $\alpha$ regulation of CD4+CD25+ T cell levels in NOD mice. Proc. Natl. Acad. Sci. U. S. A. 99:12287-12292.

17. Boyman, O., et al. 2004. Spontaneous development of psoriasis in a new animal model shows an essential role for resident $T$ cells and tumor necrosis factor-alpha. J. Exp. Med. 199:731-736.

18. Korner, H., et al. 1997. Critical points of tumor necrosis factor action in central nervous system autoimmune inflammation defined by gene targeting. J. Exp. Med. 186:1585-1590.

19. Ohashi, P.S., et al. 1993. Induction of diabetes is influenced by the infectious virus and local expression of MHC class I and tumor necrosis factoralpha. J. Immunol. 150:5185-5194.

20. Sata, M., and Walsh, K. 1998. TNF- $\alpha$ regulation of Fas ligand expression on the vascular endothelium modulates leukocyte extravasation. Nat. Med. 4:415-420

21. Kagi, D., et al. 1999. TNF receptor 1 -dependent $\beta$ cell toxicity as an effector pathway in autoimmune diabetes. J. Immunol. 162:4598-4605.

22. Kafrouni, M.I., Brown, G.R., and Thiele, D.L. 2003. The role of TNF-TNFR2 interactions in generation of CTL responses and clearance of hepatic adenovirus infection. J. Leukoc. Biol. 74:564-571.

23. Chang, I., et al. 2004. Role of calcium in pancreatic islet cell death by IFN- $\gamma / \mathrm{TNF}-\alpha$. J. Immunol. 172:7008-7014.

24. Mathis, D., Vence, L., and Benoist, C. 2001. $\beta$-Cell death during progression to diabetes. Nature. 414:792-798.

25. McKall-Faienza, K.J., et al. 1998. Absence of TNFRp55 influences virus-induced autoimmunity despite efficient lymphocytic infiltration. Int Immunol. 10:405-412.

26. Grivennikov, S.I., et al. 2005. Distinct and nonredundant in vivo functions of TNF produced by T cells and macrophages/neutrophils: protective and deleterious effects. Immunity. 22:93-104.

27. Pasparakis, M., Alexopoulou, L., Episkopou, V., and Kollias, G. 1996. Immune and inflammatory responses in TNF- $\alpha$-deficient mice: a critical requirement for TNF- $\alpha$ in the formation of primary B cell follicles, follicular dendritic cell networks and germinal centers, and in the maturation of the humoral immune response. J. Exp. Med. 184:1397-1411.

28. Hu, H.M., et al. 2002. CD28, TNF receptor, and IL-12 are critical for CD4-independent cross-priming of therapeutic antitumor CD8+ T cells. J. Immunol. 169:4897-4904

29. Herrera, P.L., Harlan, D.M., and Vassalli, P. 2000. A mouse CD8 T cell-mediated acute autoimmune diabetes independent of the perforin and Fas cytotoxic pathways: possible role of membrane TNF. Proc. Natl. Acad. Sci. U. S. A. 97:279-284.
30. Ruby, J., Bluethmann, H., and Peschon, J.J. 1997. Antiviral activity of tumor necrosis factor (TNF) is mediated via p55 and p75 TNF receptors. J. Exp. Med. 186:1591-1596.

31. Rothe, J., et al. 1993. Mice lacking the tumour necrosis factor receptor 1 are resistant to TNF-mediated toxicity but highly susceptible to infection by Listeria monocytogenes. Nature. 364:798-802

32. Kassiotis, G., Pasparakis, M., Kollias, G., and Probert, L. 1999. TNF accelerates the onset but does not alter the incidence and severity of myelin basic protein-induced experimental autoimmune encephalomyelitis. Eur. J. Immunol. 29:774-780.

33. Marino, M.W., et al. 1997. Characterization of tumor necrosis factor-deficient mice. Proc. Natl. Acad. Sci. U. S. A. 94:8093-8098.

34. Suresh, M., Singh, A., and Fischer, C. 2005. Role of tumor necrosis factor receptors in regulating CD8 T-cell responses during acute lymphocytic choriomeningitis virus infection. J. Virol. 79:202-213.

35. McSorley, S.J., et al. 1997. Immunological tolerance to a pancreatic antigen as a result of local expression of TNFalpha by islet beta cells. Immunity. 7:401-409.

36. Christen, U., and von Herrath, M.G. 2002. Apoptosis of autoreactive CD8 lymphocytes as a potential mechanism for the abrogation of type 1 diabetes by islet-specific TNF- $\alpha$ expression at a time when the autoimmune process is already ongoing. Ann. N. Y. Acad. Sci. 958:166-169.

37. Yokota, S., Geppert, T.D., and Lipsky, P.E. 1988. Enhancement of antigen- and mitogen-induced human $\mathrm{T}$ lymphocyte proliferation by tumor necrosis factor- $\alpha$. J. Immunol. 140:531-536.

38. Tartaglia, L.A., et al. 1993. Stimulation of human T-cell proliferation by specific activation of the 75-kDa tumor necrosis factor receptor. J. Immunol. 151:4637-4641

39. Kim, E.Y., and Teh, H.S. 2001. TNF type 2 receptor ( $\mathrm{p} 75)$ lowers the threshold of T cell activation. J. Immunol. 167:6812-6820.

40. Kim, E.Y., and Teh, H.S. 2004. Critical role of TNF receptor type-2 (p75) as a costimulator for IL-2 induction and $\mathrm{T}$ cell survival: a functional link to CD28. J. Immunol. 173:4500-4509.

41. Aspalter, R.M., Eibl, M.M., and Wolf, H.M. 2003. Regulation of TCR-mediated T cell activation by TNF-RII. J. Leukoc. Biol. 74:572-582.

42. Welborn, M.B., III, et al. 1996. A human tumor necrosis factor $\mathrm{p} 75$ receptor agonist stimulates in vitro $\mathrm{T}$ cell proliferation but does not produce inflammation or shock in the baboon. J. Exp. Med. 184:165-171.

43. McKenzie, J.L., Calder, V.L., Starling, G.C., and Hart, D.N. 1995. Role of tumour necrosis factor-alpha in dendritic cell-mediated primary mixed leucocyte reactions. Bone Marrow Transplant. 15:163-171.

44. Sheehan, K.C., et al. 1995. Monoclonal antibodies specific for murine p55 and p75 tumor necrosis factor receptors: identification of a novel in vivo role for p75. J. Exp. Med. 181:607-617.

45. Kim, E.Y., Priatel, J.J., Teh, S.J., and Teh, H.S. 2006. TNF receptor type 2 (p75) functions as a costimulator for antigen-driven $\mathrm{T}$ cell responses in vivo. J. Immunol. 176:1026-1035.

46. Bongartz, T., et al. 2006. Anti-TNF antibody therapy in rheumatoid arthritis and the risk of serious infections and malignancies: systematic review and meta-analysis of rare harmful effects in randomized controlled trials. JAMA. 295:2275-2285.

47. Ohashi, P.S., et al. 1991. Ablation of "tolerance" and induction of diabetes by virus infection in viral antigen transgenic mice. Cell. 65:305-317.

48. Hanahan, D. 1985. Heritable formation of pancreatic beta-cell tumours in transgenic mice expressing recombinant insulin/simian virus 40 oncogenes. Nature. 315:115-122.

49. Speiser, D.E., et al. 1997. Self antigens expressed by solid tumors do not efficiently stimulate naive or activated T cells: implications for immunotherapy. J. Exp. Med. 186:645-653.

50. Nguyen, L.T., et al. 2002. Tumor growth enhances cross-presentation leading to limited $\mathrm{T}$ cell activation without tolerance. J. Exp. Med. 195:423-435.

51. Caux, C., Dezutter-Dambuyant, C., Schmitt, D. and Banchereau, J. 1992. GM-CSF and TNF-alpha cooperate in the generation of dendritic Langerhans cells. Nature. 360:258-261.

52. Rieser, C., Bock, G., Klocker, H., Bartsch, G., and Thurnher, M. 1997. Prostaglandin E2 and tumor necrosis factor $\alpha$ cooperate to activate human dendritic cells: synergistic activation of interleukin 12 production. J. Exp. Med. 186:1603-1608.

53. Bauman, S.K., Huffnagle, G.B., and Murphy, J.W. 2003. Effects of tumor necrosis factor alpha on dendritic cell accumulation in lymph nodes draining the immunization site and the impact on the anticryptococcal cell-mediated immune response. Infect. Immun. 71:68-74

54. Suto, H., et al. 2006. Mast cell-associated TNF promotes dendritic cell migration. J. Immunol. 176:4102-4112.

55. Ritter, U., Meissner, A., Ott, J., and Korner, H. 2003. Analysis of the maturation process of dendritic cells deficient for TNF and lymphotoxin- $\alpha$ reveals an essential role for TNF. J. Leukoc. Biol. 74:216-222.

56. Moore, R.J., et al. 1999. Mice deficient in tumor necrosis factor- $\alpha$ are resistant to skin carcinogenesis. Nat. Med. 5:828-831.

57. Suganuma, M., et al. 1999. Essential role of tumor necrosis factor $\alpha$ (TNF- $\alpha$ ) in tumor promotion as revealed by TNF- $\alpha$-deficient mice. Cancer Res. 59:4516-4518.

58. Wu, T.H., et al. 2004. Long-term suppression of tumor growth by TNF requires a Stat1- and IFN regulatory factor 1-dependent IFN-gamma pathway but not IL-12 or IL-18. J. Immunol. 172:3243-3251.

59. Meager, A. 1999. Cytokine regulation of cellular adhesion molecule expression in inflammation. Cytokine Growth Factor Rev. 10:27-39.

60. Mackay, F., Loetscher, H., Stueber, D., Gehr, G., and Lesslauer, W. 1993. Tumor necrosis factor $\alpha$ (TNF- $\alpha$ )induced cell adhesion to human endothelial cells is under dominant control of one TNF receptor type, TNF-R55. J. Exp. Med. 177:1277-1286.

61. Wolf, D., et al. 2001. TNF-alpha-induced expression of adhesion molecules in the liver is under the control of TNFR1--relevance for concanavalin Ainduced hepatitis. J. Immunol. 166:1300-1307.

62. Neumann, B., et al. 1996. Crucial role of 55-kilodalton TNF receptor in TNF-induced adhesion molecule expression and leukocyte organ infiltration. J. Immunol. 156:1587-1593.

63. Mascher, B., Schlenke, P., and Seyfarth, M. 1999. Expression and kinetics of cytokines determined by intracellular staining using flow cytometry. J. Immunol. Methods. 223:115-121.

64. Hill, G.R., et al. 2000. The p55 TNF- $\alpha$ receptor plays a critical role in $\mathrm{T}$ cell alloreactivity. J. Immunol. 164:656-663

65. Brown, G.R., and Thiele, D.L. 2000. Enhancement of MHC class I-stimulated alloresponses by TNF/ TNF receptor (TNFR) 1 interactions and of MHC class II-stimulated alloresponses by TNF/TNFR2 interactions. Eur. J. Immunol. 30:2900-2907.

66. Janeway, C.A., Jr., and Medzhitov, R. 2002. Innate immune recognition. Annu. Rev. Immunol 20:197-216

67. Matzinger, P. 2002. The danger model: a renewed sense of self. Science. 296:301-305.

68. Calder, C.J., Nicholson, L.B., and Dick, A.D. 2005. A selective role for the TNF p55 receptor in autocrine signaling following IFN- $\gamma$ stimulation in experimental autoimmune uveoretinitis. J. Immunol. 175:6286-6293.

69. Nguyen, V.T., and Benveniste, E.N. 2002. Critical role 
of tumor necrosis factor- $\alpha$ and NF- $\kappa B$ in interferongamma -induced CD40 expression in microglia/ macrophages. J. Biol. Chem. 277:13796-13803.

70. Cnop, M., et al. 2005. Mechanisms of pancreatic $\beta$-cell death in type 1 and type 2 diabetes: many differences, few similarities. Diabetes. 54(Suppl. 2):S97-S107.

71. Balkwill, F., and Coussens, L.M. 2004. Cancer: an inflammatory link. Nature. 431:405-406

72. Clevers, H. 2004. At the crossroads of inflammation and cancer. Cell. 118:671-674.

73. Balkwill, F., and Mantovani, A. 2001. Inflammation and cancer: back to Virchow? Lancet. 357:539-545.

74. Karin, M., and Greten, F.R. 2005. NF-кB: linking inflammation and immunity to cancer development and progression. Nat. Rev. Immunol. 5:749-759.
75. de Visser, K.E., Eichten, A., and Coussens, L.M. 2006. Paradoxical roles of the immune system during cancer development. Nat. Rev. Cancer. 6:24-37.

76. Luo, J.L., Maeda, S., Hsu, L.C., Yagita, H., and Karin, M. 2004. Inhibition of NF- $\mathrm{KB}$ in cancer cells converts inflammation- induced tumor growth mediated by TNF $\alpha$ to TRAIL-mediated tumor regression. Cancer Cell. 6:297-305.

77. Pikarsky, E., et al. 2004. NF-אB functions as a tumour promoter in inflammation-associated cancer. Nature. 431:461-466.

78. Greten, F.R., et al. 2004. IKK $\beta$ links inflammation and tumorigenesis in a mouse model of colitisassociated cancer. Cell. 118:285-296.

79. Li, Q., Withoff, S., and Verma, I.M. 2005. Inflammation-associated cancer: NF-KB is the lynchpin.
Trends Immunol. 26:318-325.

80. Kundig, T.M., et al. 1996. Duration of TCR stimulation determines costimulatory requirement of $\mathrm{T}$ cells. Immunity. 5:41-52.

81. Nakae, S., Asano, M., Horai, R., Sakaguchi, N., and Iwakura, Y. 2001. IL-1 enhances T cell-dependent antibody production through induction of CD40 ligand and OX40 on T cells. J. Immunol. 167:90-97. 82. Sepulveda, H., Cerwenka, A., Morgan, T., and Dutton, R.W. 1999. CD28, IL-2-independent costimulatory pathways for CD8 T lymphocyte activation. J. Immunol. 163:1133-1142.

83. Pircher, H., Burki, K., Lang, R., Hengartner, H., and Zinkernagel, R.M. 1989. Tolerance induction in double specific T-cell receptor transgenic mice varies with antigen. Nature. 342:559-561. 